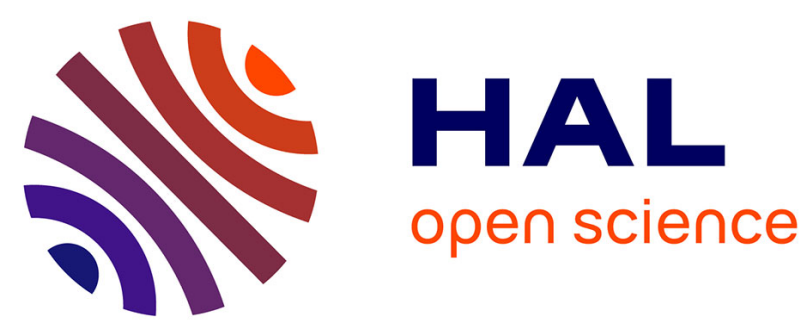

\title{
Physical chitosan microhydrogels as scaffolds for spinal cord injury restoration and axon regeneration
}

Jamila Chedly, Sylvia Soares, Alexandra Montembault, Ysander von Boxberg, Michèle Veron-Ravaille, Christine Mouffle, Marie-Noelle Benassy, Jacques Taxi, Laurent David, Fatiha Nothias

\section{To cite this version:}

Jamila Chedly, Sylvia Soares, Alexandra Montembault, Ysander von Boxberg, Michèle Veron-Ravaille, et al.. Physical chitosan microhydrogels as scaffolds for spinal cord injury restoration and axon regeneration. Biomaterials, 2017, 138, pp.91-107. 10.1016/j.biomaterials.2017.05.024 . hal-01529341

\section{HAL Id: hal-01529341 \\ https://hal.sorbonne-universite.fr/hal-01529341}

Submitted on 30 May 2017

HAL is a multi-disciplinary open access archive for the deposit and dissemination of scientific research documents, whether they are published or not. The documents may come from teaching and research institutions in France or abroad, or from public or private research centers.
L'archive ouverte pluridisciplinaire HAL, est destinée au dépôt et à la diffusion de documents scientifiques de niveau recherche, publiés ou non, émanant des établissements d'enseignement et de recherche français ou étrangers, des laboratoires publics ou privés. 


\section{Physical chitosan microhydrogels as scaffolds for spinal cord injury restoration and axon regeneration}

Jamila CHEDLY ${ }^{*}$, Sylvia SOARES ${ }^{*}$, Alexandra MONTEMBAULT ${ }^{2}$, Ysander von BOXBERG ${ }^{1}$, Michèle VERON-RAVAILLE ${ }^{1}$, Christine MOUFFLE ${ }^{1}$, Marie-Noelle BENASSY1, Jacques TAXI ${ }^{1}$, Laurent DAVID ${ }^{2}$, and Fatiha NOTHIAS ${ }^{1}$

(1) UPMC Univ Paris 06, CNRS UMR 8246, INSERM U1130, Neuroscience Paris Seine Institut de Biologie Paris Seine (NPS - IBPS), 75005 Paris, France

(2) Université Claude Bernard Lyon 1, Univ. Lyon, CNRS UMR 5223, Ingénierie des Matériaux Polymères IMP@Lyon1, 69622 Villeurbanne Cedex, France

$\left({ }^{*}\right)$ these authors contributed equally to this work

Corresponding authors: fatiha.nothias@upmc.fr; laurent.david@univ-lyon1.fr;

sylvia.soares@upmc.fr 


\section{(Abstract)}

Recovery from traumatic spinal cord injury (SCI) usually fails due to a cascade of cellular and molecular events that compromise neural tissue reconstitution by giving rise to glial scarring and cavity formation. We designed a scaffold material for SCI treatment containing only chitosan and water as fragmented physical hydrogel suspension (Chitosan-FPHS), with defined degree of acetylation (DA), polymer concentration, and mean fragment size. Implantation of Chitosan-FPHS alone into rat spinal cord immediately after a bilateral dorsal hemisection promoted reconstitution of spinal tissue and vasculature, and diminished fibrous glial scarring: with astrocyte processes primarily oriented towards the lesion, the border between lesion site and intact tissue became permissive for regrowth of numerous axons into, and for some even beyond the lesion site. Growing axons were myelinated or ensheathed by endogenous Schwann cells that migrated into the lesion site and whose survival was prolonged. Interestingly, Chitosan-FPHS also modulated the inflammatory response, and we suggest that this might contribute to tissue repair. Finally, this structural remodeling was associated with significant, long-lasting gain in locomotor function recovery. Because it effectively induces neural tissue repair, Chitosan-FPHS biomaterial may be a promising new approach to treat SCI, and a suitable substrate to combine with other strategies. 


\section{(Introduction)}

Traumatic injuries of the spinal cord (SCI) can lead to life-long loss of sensation and voluntary motor functions. Although severed adult neurons of the mammalian central nervous system (CNS) can initially survive, regrowth of their axons through the lesion site ultimately fails due to a cascade of cellular and molecular events leaving the affected neural tissue in a permanently altered, regeneration-inhibited state (for review, see 1, 2). A further complication is that injury-associated vascular damage inevitably includes hypoxia, hemorrhage and edema that accelerate necrosis of damaged neural tissue. The associated breakdown of the blood-spinal cord barrier favors infiltration of bloodderived monocytes/macrophages that, together with activated microglia, spread inflammation beyond the initial lesion site, contributing to secondary expansion of the lesion. The tissue cavities that develop because of necrosis become walled off by the astrocytic scar, creating a mechanical, and chemical barrier to axon growth due to expression of inhibitory molecules such as CSPG, as well as semaphorins, and matrixmetalloproteinases. Axon regrowth is further inhibited by central myelin degradation products, namely MAG (myelin associated glycoprotein), Omgp (oligodendrocyte myelin glycoprotein), and Nogo, and also by low levels of neurotrophic factors (for review, see $3,4)$.

To overcome these hurdles, implantable biomaterials have recently gained interest in the treatment of SCI. To be effective, these biomaterials must first bridge the gap created by the lesion in the spinal tissue by forming an extracellular matrix replacement that supports anchoring of cells and promotes axon growth. Secondly, they should reduce tissue cavitation and glial scarring, allowing for efficient neo-vascularization. Thirdly, and importantly, they need to participate in modulating the long-term inflammatory response $(5,6)$.

Scaffold materials to treat SCI can be entirely synthetic polymers, such as PLA (poly-Llactic acid and polylactide copolymers; 7), PHEMA/MMA (poly-(2-hydroxyethyl methacrylate-co-methyl methacrylate]; 8), or PEG (polyethylene glycol; 9); or can be derivatives of naturally occurring polymers, like fibrin (10), alginate (11), or chitosan $(12,13)$. The biodegradability of these components can vary from non-degradable to 
rapidly degrading biomaterials. Some materials can be electrospun to form solid fibers; most come in the form of hydrogels (containing $>70 \%$ water) that can either be implanted, or form a gel in situ from an aqueous solution. These scaffolds may also be used to deliver growth-promoting molecules, and/or can contain grafted cells favoring neural tissue regeneration and myelination of regrowing axons (for review, see 14).

Chitosan, used in our novel biomaterial for SCI treatment, is prepared by partial $\mathrm{N}$ deacetylation of chitin, a natural polysaccharide obtained from the exoskeleton of crustaceans, the cell wall of fungi, and or from squid pens. The physicochemical properties of chitosan can be modulated, in particular through the variation and control of its average degree of acetylation $(D A)$. Chitosan-based materials and derivatives have received increased attention in tissue engineering because of their unique and appealing properties such as cytocompatibility, biodegradability, and nontoxicity. They have been extensively evaluated for regeneration of epithelial and soft tissues (15), and their beneficial characteristics include preservation of cellular phenotypes, activity enhancement of bound bioactive factors, as well as the stimulation of synthesis of tissuespecific extracellular matrix $(16,17)$. In addition, it has antitumor activity, as well as analgesic, hemostatic, anticholesterolemic, antimicrobial, and antioxidant effects (for review, 13,15).

In treating SCI, chitosan has been successfully employed in the form of collagen-filled or stem cell-seeded preformed tubes designed to bridge the tissue gap created by transection of rat spinal cord $(12,18-21)$. However, these studies did not evaluate the therapeutic potential of the chitosan biomaterial alone. The impact of the hydrogel implant itself on scar formation, inflammation, and vascularization was not analyzed, with one exception (12) reporting that chitosan did not provoke a higher than normal inflammatory reaction. Efficacy of the chitosan-biomaterial alone could provide major advantages as a therapeutic agent, avoiding potential safety issues encountered by cotreatments with cell based therapies, and making it easier for its large scale production for clinical testing. In the present study, we evaluated the reaction of lesioned spinal cord tissue to a pure chitosan-based implant in form of a newly designed formulation as a Fragmented Physical Hydrogel Suspension (Chitosan-FPHS) with well 
defined physico-chemical characteristics, i.e. molecular weight, acetylation degree, polymer concentration, and range of fragment size. 


\section{Materials \& methods}

\section{Preparation of Chitosan-FPHS}

Chitosan powder from squid pens (Mahtani Chitosan, Veraval, India; batch index 114) was dissolved in acetic acid aqueous solution, pressure-filtered through successively narrower Millipore filters $(3.0,1.2$, and $0.45 \mu \mathrm{m}$ pore size $)$, and re-precipitated by mixing with concentrated ammonia solution. Precipitates were washed in deionized water until neutral pH was achieved, and finally freeze-dried before further use. Number average and weight average molar masses $\left(\mathrm{M}_{n}\right.$ and $\left.\mathrm{M}_{\mathrm{w}}\right)$ were determined by size exclusion chromatography coupled with refractive index measurements and multiple light scattering (Wyatt Dawn EOS multi-angles operated at $690 \mathrm{~nm}$ ), according to our previous work (22). The degree of acetylation $(D A)$ was analyzed by ${ }^{1} \mathrm{H}-\mathrm{NMR}$ spectroscopy on chitosan $(10 \mathrm{mg} / \mathrm{mL})$ dissolved in $\mathrm{D}_{2} \mathrm{O}$ acidified with $5 \mu \mathrm{L} / \mathrm{mL}$ of concentrated $\mathrm{HCl}$ according to the method of Hirai (23). Reacetylation of chitosan was performed by dropwise addition of stoichiometric amounts of acetic anhydride ( $>99 \%$ purity, Sigma) to a $1 \% \mathrm{w} / \mathrm{v}$ chitosan solution, then letting the reaction continue overnight before re-precipitating the polymer with concentrated ammonia, again followed by washing steps and lyophilisation (for details see 16, and refs. therein).

A $2.5 \% \mathrm{w} / \mathrm{w}$ aqueous solution of filtered chitosan, obtained by addition of a stoichiometrically determined amount of acetic acid to protonate amine groups of chitosan, was poured into a $35 \mathrm{~mm}$ Petri dish. Chitosan hydrogel formation was achieved by placing the Petri dish over a source of concentrated ammonia vapors (generated with an aqueous ammonia solution, $1 \mathrm{M}$ ) for $15 \mathrm{~h}$, and the resulting chitosan monolithic gel was washed in deionized water until a neutral $\mathrm{pH}$ was obtained in the washing bath. This final hydrogel only contains chitosan and water at a concentration close to that of the initial solution $(22,24)$. Evaluation of the viscoelastic properties and mechanical behavior of such bulk hydrogels was done according to our previous work $(22,24)$. The storage modulus at equilibrium corresponding to the plateau value of $G^{\prime}$ measured at low angular frequency ( $\left.\sim 10^{-2} \mathrm{rad} / \mathrm{s}\right)$ of our final hydrogel was close to $1300 \mathrm{~Pa}$ (for more details, see 24). The gel was then fragmented by blending in deionized water with an Ultra Turrax ${ }^{\circledR}$ (IKA) homogenizer $(10 \%[\mathrm{w} / \mathrm{w}]$ of gel in deionized water, rotation speed 11000 rpm; 4 x 20 sec; Fig. 1A). Blending time and rotation speed were chosen so 
that the fragmented suspension had a median fragment size of about $20 \mu \mathrm{m}$. The suspension was autoclaved at $121^{\circ} \mathrm{C}$ for $20 \mathrm{~min}$., and finally kept at room temperature. The chitosan used in this study had a $D A$ of $4 \%+/-0.5 \%$, a $M_{w}$ of about $550+/-50 \mathrm{~kg} / \mathrm{mol}$, a dispersity $Ð$ (equal to $M_{w} / M_{n}$ ) of $1.5+/-0.3$ (22). Such high molecular masses enable the preparation of hydrogels at low concentration $(\mathrm{Cp}>1 \% \mathrm{w} / \mathrm{w})$, here $2.5 \%$. The initial suspension was centrifuged (Sigma 3K30 at $13000 \mathrm{rpm}, 30 \mathrm{~s}$ ) and the pellet was collected. The apparent viscosity of the Chitosan-FPHS paste was determined as shown in Fig. 1B. Hydrogels prepared from high DA chitosan $(38 \%+/-2 \%$; obtained by reacetylation of low DA chitosan) but the same fragment size as above (20 $\mu \mathrm{m})$, as well as a hydrogel with low DA (4\%, Fig. 1A) but much larger fragment size $(\sim 150 \mu \mathrm{m}$, Fig. 1A) were also tested. The Chitosan-FPHS preparation was based on the procedure described in Nothias et al. (25).

\section{Animals}

Adult female Wistar rats (230-250g; total number of animals: 84; Janvier, France) were used throughout this study, housed in the animal facilities at the IBPS institute. All experimental procedures and animal care were in accordance with 2010/63/UE European directive and French decree 2013-118, and approved by the Institutional Animal Care and Ethics Committee at the UPMC (\#1514.01). Before and after surgical interventions animals were provided food and water ad libitum. During surgery, and until they awoke from anesthesia, animals were placed on a heating pad to maintain body temperature. To relieve post-operative pain, rats received intraperitoneal injections of Buprenorphine $(0.3 \mathrm{mg} / \mathrm{mL}$, Axience, France) twice a day during the first week post-lesion, and intramuscular injections of gentamycin (Pangram 4\%, Virbac, France) to prevent urinary infections. Until restoration of normal micturition, bladders were manually emptied twice a day, and the health state of operated rats was monitored by regular weight.

\section{Spinal cord injury and Chitosan-FPHS implantation}

Animals were anesthetized by intraperitoneal injection of a solution of xylazine (5mg/kg; Rompun 2\%, Bayer, France) and ketamine (50mg/kg; Imalgene 1000, RhoneMerieux, France). After laminectomy at thoracic levels 8/9 (th 8/9) a longitudinal incision was made in the dura mater, the spinal cord exposed, and a bilateral dorsal 
over-hemisection was made with micro-scissors, followed by passing an ophtalmic micro- scalpel (blade angle $15^{\circ}$, Micro Feather no. 715) three times through the lesion to assure complete ablation of dorsal fiber pathways down to below the central canal ( $c f$. 26). Half of the animals received an implantation of Chitosan-FPHS (about $3 \mu \mathrm{l}$ ) immediately after the dorsal hemisection (lesion-Chito group, to be compared with lesion-only animals). Finally, muscles were sutured, and the skin closed using clips. It should be noted that once implanted, the dense suspension of Chitosan-FPHS, obtained by brief centrifugation, does not leak and stays within the lesion site without any additional manipulation.

\section{Immunohistochemistry}

After survival times of 2 weeks (2w), 4w, 8w, 10w, and 12w, animals were deeply anesthetized by intraperitoneal injection of sodium pentobarbital $(100 \mathrm{mg} / \mathrm{kg}$, Ceva), and transcardially perfused first with saline, then with $4 \%$ paraformaldehyde (PFA, Sigma) in $0.1 \mathrm{M}$ phosphate buffer. Spinal cords were dissected, post-fixed in the same PFA solution, cryoprotected by soaking in $15 \%$ and $30 \%$ sucrose for $24 \mathrm{~h}$, and $48 \mathrm{~h}$ at $4{ }^{\circ} \mathrm{C}$, respectively, then frozen at $-40^{\circ} \mathrm{C}$ in isopentane, and stored at $-80^{\circ} \mathrm{C}$. $30 \mu \mathrm{m}$ horizontal sections were prepared on a cryostat (Leica CM3050 S), and mounted on Superfrost slides (VWR).

For immunolabeling, sections were rinsed in phosphate buffered saline (PBS), and incubated for $1 \mathrm{~h}$ in a blocking solution containing $0.2 \%$ gelatin, $0.25 \%$ Triton-X100, $1 \%$ of a $0.1 \mathrm{M}$ solution of L-lysine, and $0.1 \%$ thimerosal (all Sigma) in PBS, before incubation overnight at room temperature with primary antibodies in the same solution. After thorough rinsing in PBS, sections were incubated for $2 \mathrm{~h}$ with appropriate Alexa-488 (1:700), or Alexa-555 (1:1000) -coupled secondary antibodies (Life Technologies), and mounted in Mowiol. The following primary antibodies were used: rabbit- $\alpha$-glial fibrillary acidic protein, commonly used to reveal astrocytes (GFAP; Dako, 1:2000); mouse- $\alpha$-nestin (intermediate filament protein characteristic of immature neural cells; Millipore, 1:1000); mouse anti-ß3 tubulin, Tuj-1 (neuron-specific; Covance, 1:1500); mouse anti-neurofilament SMI 31 and 32 (Affiniti/Sternberg, 1:2000); rabbit- $\alpha$-5HT (5hydroxytryptophan, revealing serotoninergic fibers; Sigma, 1:5000); mouse- $\alpha$ synaptophysin (Sigma, 1:500, France); rabbit- $\alpha$-CGRP (calcitonin gene-related peptide, recognizing a subtype of primary sensory afferents; Biovalley, 1:10,000); mouse-SMI 71 
to reveal mature blood vessels (Covance, 1:100); rabbit- $\alpha$-Olig2 (oligodendrocytespecific transcription factor; Chemicon, 1:500); mouse- $\alpha$-MBP (Myelin Basic Protein; Millipore, 1:50); chick- $\alpha$-myelin protein zero (P0; Novus, 1:300); mouse- $\alpha$-rat ED1 (macrophage/monocyte-specific antigen; Chemicon, 1:100); rabbit- $\alpha$-CD206 (macrophage mannose receptor; Santa Cruz, 1:500); rabbit- $\alpha$-CD86 (activated Blymphocyte and monocyte antigen; Abcam, 1:500); rabbit- $\alpha$-laminin (Sigma, 1:100); goat- $\alpha$-collagen type IV (Millipore, 1:10,000); rabbit- $\alpha$-fibronectin (Sigma, 1:500); mouse- $\alpha$-chondroitin sulphate proteoglycan (CS-56; Sigma, 1:200); rabbit- $\alpha$-NG2 proteoglycan (Chemicon, 1:500). Sections were mounted in Mowiol (Calbiochem), or in CFM3 (see 27).

\section{Anterograde and retrograde axon tracing}

For tracing of myelinated primary sensory afferents, animals were anesthetized as above, and right and left sciatic nerves exposed by opening overlying skin and muscles. Via a small incision into the epineurium at mid-thigh level, $3 \mu \mathrm{l}$ of a $1 \%$ cholera toxin-B (CTB, Sigma) solution in PBS were injected with the help of a Hamilton syringe, left in place for $5 \mathrm{~min}$. Uptake of CTB by axons was enhanced by slightly crushing the proximal part of the nerve with forceps. Finally, muscle and skin were sutured. After one week, animals were sacrificed and sections prepared as above. CTB was detected using goat- $\alpha-$ CTB antibodies (1/2000, Calbiochem).

Tracing of corticospinal tract (CST) axons was achieved by stereotaxic injection of a $10 \%$ solution of biotin dextran amine (BDA 10,000; Molecular Probes) in saline into the left and right motor cortices with a Hamilton syringe at the following coordinates (Bregma: 1, $-2,-3$; depth: $1.75 \mathrm{~cm}$; lateral: \pm 2 et $\pm 3 \mathrm{~cm})$. 8 injections $(0.5 \mu \mathrm{l}$ each) were made per side to cover the motor cortex area. Animals were perfused after two weeks, and the BDA tracer visualized on spinal cord sections by Alexa-555 or -488 conjugated streptavidin (1:2000; Invitrogen).

Estimation of the proportion of CGRP- and 5HT-positive fibers relative to the total number of Tuj1-positive fibers

For lesion-Chito animals, 10 weeks post-lesion, horizontal sections at the level of the injury site were double immunostained for CGRP/Tuj1, and 5HT/Tuj1 (2 animals for 
CGRP/Tuj1, 3-4 sections per animal; 3 animals for 5HT/Tuj1, 2-5 sections per animal). Particle analysis was then quantified with Fiji software on confocal microscope (Leica TCS SP5) images of the sections. After defining a threshold, particle values for CGRP and $5 \mathrm{HT}$ immunoreactivity were compared to those of Tuj1.

\section{Vascular pattern}

The angio-architectony within the lesion-implant site was analyzed at 10 weeks postlesion by carefully dissecting the spinal cord from non - perfused animals, fixation in $4 \%$ paraformaldehyde (PFA) in 0.1M PBS, and application of the Pickworth technique on tissue sections prepared from the lesion site (benzidin-peroxide method to stain hemoglobin; 28).

\section{Lesion cavity analysis}

For each animal analyzed, 3 horizontal sections through the lesion center were chosen (i.e., sections exhibiting the relatively largest lesion site/cavity surface, as delimited by GFAP staining). On each section, the primary lesion area and all secondary lesion cavities (extending $0,5 \mathrm{~cm}$ in both rostral and caudal direction) were surrounded using Fiji software, with the total lesion cavity surface thus representing the summed up surface of the primary plus adjacent secondary lesions.

\section{Transmission electron microscopy}

Rats were deeply anesthetized as above and perfused first with phosphate buffer (PB), then with $60 \mathrm{~mL}$ of a solution of picric acid (2,4,6-trinitrophenol; saturated solution, about $1.2 \%$ ) in PB with 1.4\% PFA and $0.05 \%$ glutaraldehyde. After dissection, pieces of spinal cord containing the lesion site were postfixed overnight at $4^{\circ} \mathrm{C}$ in the same fixative, washed, mounted in albumin-gelatin supplemented with $1.25 \%$ glutaraldehyde, and cut into 70-100 $\mu$ m slices on a vibratome (Leica VT1000E), which were then treated with $2.5 \%$ osmium for $2-3 \mathrm{~h}$, washed again in $\mathrm{PB}$, then in water, before being dehydrated in an ethanol series and mounted in Durcupan resin (Sigma). Ultrathin sections were cut on a Reichert Ultracut-S microtome (Leica), mounted on grids, treated with lead citrate/uranyl acetate, and analyzed on a Zeiss 912 Omega electron microscope (see also 29). 


\section{Western blotting}

After post-operation survival times of 4 days (4d), 1 week (1w), 2w, $4 w$, and $8 w$, the spinal cord lesion site was carefully dissected on ice, and directly subjected to lysis by homogenizing in an Eppendorf cup with a conical Teflon pestel in ice-cold RIPA lysis buffer supplemented with protease inhibitor cocktail (Sigma P8340). Protein concentration was equilibrated between samples to $4 \mathrm{mg} / \mathrm{mL}$, samples were mixed with 2x Laemmli buffer, heated to $95^{\circ} \mathrm{C}$ for $5 \mathrm{~min}$, and kept frozen until electrophoresis on $7 \%$ or $9 \%$ ultrathin polyacrylamide gels (30). After transfer of proteins onto nitrocellulose membrane (GE Healthcare) and blocking of membranes with 5\% non-fat milk powder, or $5 \%$ bovine serum albumin in PBS, the following antibodies were used to assess the relative abundance of M1- vs. M2-type macrophage marker proteins, as well as GFAP within the injury site at different time-points post-lesion: rabbit- $\alpha$-CD86 (Abcam 53004, 1:1000); rabbit- $\alpha$-iNOS (NOS2; Santa Cruz, sc-651, 1:150); goat- $\alpha$-CD206 (mannose receptor; Santa Cruz sc-34577, 1:200); goat- $\alpha$-Arginase-1 (Sigma SAB2500101, 1:150); rabbit- $\alpha$-CD68 (Santa Cruz sc-9193, 1:1000); rabbit- $\alpha-$ GFAP (Dako, <1:100,000); loading controls: mouse- $\alpha-G A P D H ~(S a n t a$ Cruz sc-32233, 1:500); mouse- $\alpha$-actin (Santa Cruz sc-47778, 1:500). Incubation with primary antibodies for $5 \mathrm{~h}$ at $\mathrm{RT}$, or overnight at $4^{\circ} \mathrm{C}$, was followed by $2 \mathrm{~h}$ incubation with appropriate alkaline phosphatase-coupled secondary antibodies (Jackson ImmunoResearch, 1:5000), and visualization by BCIP/NBT reagents in Tris/ $\mathrm{Mg}^{++}$buffer $\mathrm{pH}$ 9.5. Loading of equal protein amounts was also verified by colloidal gold total protein staining (BioRad) of Western blots run in parallel. After scanning of Western blots $(n=3$ independent experiments, 24 rats in total), band densities were evaluated and compared using Fiji software (NIH ImageJ). For each individual Western blot, after deduction of background staining, relative variations in band intensity were calculated against the density value obtained for the sample "4 days lesion-only" that was arbitrarily set to 1 . In this way, the problem of variability in overall staining intensity of blots was eliminated, and mean and S.D. values were determined for each condition (time-point post-lesion and treatment) from the relative values obtained in the 3 experiments.

\section{Bone marrow macrophage cultures}

Bone marrow macrophages (BMM) were prepared from C57/bl6 mice and cultured as described (31). Briefly, at least one femur was dissected, freed of muscle and connective 
tissue, and briefly sterilized in 70\% ethanol before cutting off both ends and ejecting the bone marrow using a PBS-filled syringe equipped with a 25G gauge needle. Bone marrow cells were resuspended and seeded in $100 \mathrm{~mm}$ non-tissue culture plastic dishes ( $4 \times 10^{5}$ cells/dish) in complete BMM medium (DMEM/F12 [Invitrogen] containing 10\% fetal calf serum, 1\% penicillin/streptomycin [Sigma] and 20\% fibroblast cell line L929conditioned medium). After reaching confluence (7-8 d in culture), monocytes were detached for further treatment using a solution of 5 mM EGTA in PBS pH 7.6.

6-well culture plates were evenly covered (or left untreated) with a dense suspension of Chitosan-FPHS that was left to dry onto the culture plastic dishes for $24 \mathrm{~h}$, and was rehydrated with culture medium $1 \mathrm{~h}$ before seeding of cells. Monocytes were grown for $2 \mathrm{~d}$ until near confluence before being polarized towards the M1 or the M2a phenotypes, by exposure to either $25 \mathrm{ng} / \mathrm{mL}$ murine recombinant IFN- $\gamma$ (Peprotech; 6h) followed by $100 \mathrm{ng} / \mathrm{mL}$ LPS (Sigma; overnight), or $15 \mathrm{ng} / \mathrm{mL}$ murine recombinant IL-4 (Peprotech; overnight), respectively. For Western blotting, culture wells were carefully rinsed twice with PBS, and cells with or without Chitosan-FPHS coating scraped off and lysed directly in Laemmli $2 x$ SDS buffer (100 $\mu \mathrm{L}$ per well). Samples were immediately heated to $95^{\circ} \mathrm{C}$ for $5 \mathrm{~min}$, then kept frozen until use. Evaluation of relative changes in macrophage marker protein expression by Western blotting ( $\mathrm{n}=3$ independent experiments) was done as above, with band density values for lesion-only samples on individual Western blots arbitrarily set to 1 .

\section{Behavioral testing}

Open-field locomotion of rats having received a spinal cord hemisection with or without Chitosan-FPHS implantation was evaluated according to the standard Basso-BeattieBresnahan (BBB) locomotor scale (32). BBB scores were assessed a day before (d-1), and the day after $(d+1)$ surgical intervention, and then once a week for a total period of 10 weeks. Animals exhibiting a score above 0 on $d+1$ were dismissed from further analysis. For each session, animals were placed under careful visual inspection in the open field, and camera-recorded for $4 \mathrm{~min}$. Two trained persons independently evaluated the rat locomotor score, and BBB scores were calculated as means of the individual scores assigned by the observers, none informed of the particular treatment the animals had received.

On rats capable of weight support on their hind legs, a more detailed, automated and 
quantitative gait analysis of locomotion was performed using a GaitLab apparatus for rodents (ViewPoint, France), based on the CatWalk method (33). The system consists of a transparent $125 \mathrm{~cm}$ long runway illuminated by a fluorescent tube. When an object (i.e., rat paws) touches the surface, the contact area lights up, detected by a video camera positioned underneath that monitors the advance of the animal across the runway.

To record baseline scores, animals were trained one week before surgery to walk across the runway until they voluntarily performed the exercise (3-4 correct crossings), the most regular crossing being selected for footprint analysis by dedicated Viewpoint software. When animals had regained frequent weight-supported stepping, the GaitLab test was repeated once a week until 10 weeks post-operation.

\section{Blinding procedure and statistics}

To ensure homogeneity of traumatic spinal cord lesions, as well as Chitosan-FPHS implantations between individual animals, they were all performed by the same person (F.N.). Operated rats were then placed in individual cages that were randomly (i.e., without any reference to the treatment) numbered by a second person, who kept the key secret during behavioral testing.

Statistical analysis and graphing was performed with GraphPad Prism software, the significance tests used are specified in the Results section and/or the figure legends, and results are indicated as mean + /- S.E.M. 


\section{RESULTS}

\section{Design and selection of a Chitosan-based scaffold material for SCI repair}

Based on our previous studies on the preparation of crosslinker-free chitosan physical hydrogels for different applications in tissue engineering $(16,17,24)$, we developed an implantable formulation in form of a suspension of physical hydrogel fragments. To this end, a high molecular weight chitosan (Mw $550 \mathrm{~kg} / \mathrm{mol}$ ) was dissolved at a concentration of $2.5 \% \mathrm{w} / \mathrm{w}$ (these parameters were kept constant throughout this study). The solution was then jellied in contact with ammonia vapors to form a physical hydrogel. After thorough washing, this hydrogel contains only chitosan and water. The hydrogel then underwent fragmentation to form a micro-suspension of particles of controlled median size, Chitosan-FPHS. The steps of preparation, and the apparent viscosity of Chitosan-FPHS are outlined in Fig. 1. This Chitosan-FPHS formulation appeared particularly suitable, as filling the lesion site can be easily accomplished by injecting a suspension of hydrogel particles. At the same time, fragmentation enhances the overall hydrogel surface immediately available for cell adhesion and colonization of the scaffold. For our preliminary feasibility experiments of Chitosan-FPHS implantation in a rat spinal cord hemisection model, two parameters were varied, and indeed found to be critical for the lesion outcome: fragment size and degree of acetylation (DA). Thus, implantation of Chitosan-FPHS with a DA of $4 \%$ and a median fragment size of about $150 \mu \mathrm{m}$ (see Fig. 1A) resulted in very limited invasion of cells, and only very few axons penetrating into the implant site (Supp. 1A), in striking contrast to Chitosan-FPHS with much smaller particle size ( $20 \mu \mathrm{m}$; Fig. 1A; see below, and Fig. 2). Two different DAs of chitosan were also tested, one relatively high (38\%), the other low (4\%), both with the same small fragment size $(\sim 20 \mu \mathrm{m})$. Implantation of high DA Chitosan-FPHS, while allowing for invasion of cells, provoked a very strong, probably deleterious inflammatory reaction, giving rise to tissue necrosis (Supp. 1B). The Chitosan-FPHS formulation finally used for more investigation for SCI repair in the following experiments thus had a mean particle size of $\sim 20 \mu \mathrm{m}$, and a DA of $4 \%$.

\section{Implantation of Chitosan-FPHS into the site of SCI modulates astrocytic reaction and scar formation}

Chitosan-FPHS with the above chosen characteristics ( $\sim 20 \mu \mathrm{m}$ particle size, 4\% DA) was implanted into the site of a bilateral dorsal spinal cord over-hemisection, and its ability 
to reduce astrocytic scar formation and cystic cavitation determined. In untreated, lesion-only spinal cord, astrocytes underwent astrogliosis the 2 first weeks after the sectioning, with their processes becoming hypertrophic, and levels of GFAP immunostaining increasing around the injury site. A compact glial scar formed around the cavity by 4 weeks post-lesion (Fig. 2A). In lesion-Chito animals, the chitosan scaffolds filled the initial lesion site, and promoted rapid cell invasion into the lesion site at the inter-particle space, as seen by Dapi nuclear staining. Integration of chitosan scaffolds into the surrounding spinal tissue efficiently prevented formation of a primary lesion cavity, while at long term small cavities were observed outside the lesion-implant site, associated with secondary lesions (Fig. 2K).

Two weeks after the lesion the astrocytic reaction in lesion-Chito animals resembled that observed in lesion-only animals. However, unlike the lesion-only animals, there was no apparent change in the astrocytic reaction thereafter from 4 weeks on and up 12 weeks post-operation. Compared to the lesion-only animals, the GFAP-immunostaining was less intense, and the astrocytic network that formed around the lesion-Chito implant site less compact (Fig. 2B). The diminished astrocytic reaction after ChitosanFPHS implantation was also observed with Western blot analysis of GFAP levels in lesion-Chito vs. lesion-only tissues, notably at 4 and 8 weeks post-operation (Fig. 2J). In addition, astrocytes located at the edge of the lesion-Chito implant site exhibited a morphology that appeared less atrophied than in lesion-only controls (Fig. 2D and F), and the astrocytic processes remained oriented toward the lesion-Chito center from one week post-operation onwards, a few of them even extended into the implant (Fig 2D, G, and $\mathbf{H}$ ). Moreover, on closer examination, the zone of axon entry into the lesion-Chito implant site revealed a clear association of axons with astrocyte processes, as illustrated by a 3-dimensional confocal microscopy analysis (Fig. 2H). This feature of the ChitosanFPHS treatment was observed at all time-points analyzed, whereas in lesion-only animals an association between astrocyte processes and axons was observed only at early stages, i.e. before 2 weeks post-injury, similar to what we have previously reported (34). These findings indicate that the Chitosan-FPHS integrates into the injury site and diminishes the strong fibrous astrogliosis and cavity formation of SCI. However, double immunostaining for CSPG and GFAP on spinal cord sections from lesion-Chito and lesion-only animals at 4 weeks post-operation revealed that CSPG is detected under 
both conditions, with no apparent difference in immunostaining intensity. In both conditions, CSPG is distributed mainly in the area of astrocyte localization, exhibiting the same network as that of GFAP-positive processes. Interestingly, double immunostaining of axons (with Tuj-1 for beta3-tubulin) and GFAP on adjacent spinal cord sections from lesion-Chito animals shows that CSPG is also located along $\mathrm{GFAP}^{+}$extensions that are associated with axons growing into the implant (Supp. 2).

\section{Chitosan-FPHS scaffolds allow for important axon regrowth into the SCI lesion site}

We visualized the ability of Chitosan-FPHS scaffolds to increase axon remodeling in the lesioned spinal cord using SMI31/32 antibodies to detect neurofilaments, or Tuj-1 to detect beta-III-tubulin. In lesion-only animals, axons could be observed at the injury site within the two first weeks post-injury, but after that time their density diminished, similar to what we have previously reported (35). In lesion-Chito animals, even at the earliest recorded times after the lesions, the number of axons and their extensions from the borders into the center of the lesion-implant site was significantly higher than in lesion-only animals (Fig. 2I). At the host-implant interface, numerous axons entered from the spinal cord into both the rostral and caudal portions of the implant site. The presence of a high density of axons within the lesion-Chito implant site was prolonged and did not subside, in contrast to the non-treated lesion-only animals in which axons were no longer detected over time (here 10 weeks) due to cavity formation (Fig. 2I).

To determine the source of axonal input to the injury site induced by the Chitosan-FPHS implant, we studied lesion-Chito animals 12 weeks post-operation. Fig 3 shows in the lesion-Chito implant site the presence of primary sensory fibers, detected either by CTBtracing from the sciatic nerve for myelinated fibers (Fig. 3D-F), or by CGRPimmunostaining for non- or weakly myelinated fibers (Fig. 3G-I). Numerous serotoninergic $\left(5 \mathrm{HT}^{+}\right)$fibers could be detected growing around the implant, some of them also within the implant site itself (Fig. 3J-L). There was also massive sprouting of $5 \mathrm{HT}^{+}$fibers ventral and caudal to the lesion site (Fig. 3M-0). BDA-tracing from the motor cortex showed that some cortico-spinal tract fibers also entered the implant. These fibers appeared to be capable of growing across the implant site, with some of them exiting into the spinal segment caudal to the lesion (Fig. 3A-C). This finding is of interest because it indicates that axon regrowth may occur over long distances. Comparison of the number of $\mathrm{CGRP}^{+}$and $5 \mathrm{HT}^{+}$fibers to that of all Tuj $1^{+}$fibers suggests 
that a considerable part of the fibers growing within the lesion-Chito implant site do not originate from areas distant from the lesion site (i.e. brain, or periphery), but rather from adjacent spinal segments (these latter being excluded from our analysis of fiber sources). Thus, CGRP+ fibers for example represent 4.1\% +/-1.3\%, 5 $\mathrm{HT}^{+}$fibers $3.8 \%+/-$ $0.9 \%$ of all Tuj $1^{+}$fibers.

\section{Impact of Chitosan-FPHS implantation on inflammatory reaction and macrophage polarization}

Inflammation is a critical mechanism underlying secondary damage after SCI (36). Following the immediate activation of local microglia after SCI, the subsequent breakdown of the blood-spinal cord barrier is accompanied by invasion of inflammatory cells into the lesion site. After an early, but transient invasion of leucocytes there is a delayed infiltration into the lesion site of lymphocytes (37-39), and blood-derived monocytes/macrophages starting 4 days post-lesion, that continues for months and that can't be easily distinguished from activated microglia. Macrophages are generally classified into two main categories, "classically activated", pro-inflammatory macrophages (M1) that provoke secondary damage, and "alternatively activated", antiinflammatory (M2) macrophages, capable of initiating tissue repair. Subclasses of the M2 phenotype have been identified. Macrophages have the capacity to dynamically switch from one phenotype to another depending on the micro-environmental factors $(40,41)$. Although initially present in the lesion, macrophages of the beneficial M2 phenotype tend to disappear about 1 week post-lesion after mouse SCI, while the proinflammatory M1 type remains (42).

To test whether the Chitosan-FPHS implant may have a beneficial effect on the inflammatory reaction following $\mathrm{SCI}$, we analyzed relative levels of M1 (CD86+), M2 (CD206+ ${ }^{+}$mannose receptor] and Arginase- $1^{+}$), and pan-macrophage/monocyte (CD68 ${ }^{+}$) marker protein expression by Western blotting at various time-points after surgery (Fig. 4). Quantitative evaluation of Western blots (Fig. 4C) shows that throughout the postlesion period examined, relative levels of the M2 marker protein CD206 were higher in lesion-Chito than in lesion-only animals (significant from 4 weeks post-lesion onwards). Arginase-1 (Arg-1) expression, also considered as an M2 marker expressed early during the immune response, was about 5-fold higher in lesion-Chito vs. lesion-only tissue at 1 
week post-lesion, and was still found at 4 weeks post-operation, while being hardly detectable in lesion-only samples. In contrast, CD86 (M1 marker protein) levels were generally higher in lesioned untreated tissue, the difference becoming significant at later stages ( 8 weeks post-injury). The pan-macrophage/monocyte marker $\left(\mathrm{CD}^{+} 8^{+}\right)$, while showing no significant difference between lesion-only and lesion-Chito animals, revealed that the inflammatory reaction is strongest during the first days post-operation (as seen at 4 days), drops at 1 week and progressively decreases thereafter, but remains detectable at later stages in both experimental conditions (8 weeks).

Supporting the results of our Western blotting, immunohistochemical staining of tissue sections from the lesion site showed a pronounced expression of CD206 ${ }^{+}-\mathrm{M} 2$ macrophages within the lesion-Chito site (Supp. 3A,C,D) compared to CD86+-M1 macrophages whose density was higher in the lesion-only tissue (Supp. 3B,E). Double immunostaining for CD206 or CD86 with ED-1, a marker for phagocytic macrophages/microglia, indicated that ED-1 expression was mostly associated with $\mathrm{CD}^{206^{+}}$, rather than CD86+ macrophages, particularly within the Chitosan-FPHS implant. Interestingly, the morphology of $\mathrm{CD}_{206^{+}}$macrophages was seen to change from a bipolar one with short processes at the host-implant border (Supp. 3C), to a rounded, amoeboid shape within the implant, with colocalization of ED1 and CD206 on the same cells (Supp. 3D). Although the overall density of CD206 ${ }^{+}$cells decreased at later stages after the lesion (10 weeks), numerous M2 macrophages could still be detected within the lesion-Chito implant site, in agreement with the Western blot results (Supp. 3 F-I).

To address the question whether Chitosan-FPHS by itself can influence macrophage polarization, we cultured mouse bone marrow-derived macrophages, polarized towards the M1 or M2 phenotype, on normal tissue culture plastic (control) vs. a substrate composed of the same Chitosan-FPHS used in the in vivo implantation experiments. Western blotting of protein extracts from these macrophage cultures revealed that on Chitosan-FPHS substrate, expression of M1 marker protein iNOS by M1-polarized macrophages was reduced by $60 \%\left(+/-6 \% ;{ }^{*} \mathrm{p}=0,001\right)$ compared to controls, while in contrast, expression of M2 marker proteins Arg-1 and Ym1/2 by M2-polarized macrophages was enhanced $(330 \%+/-53 \%(* * \mathrm{p}=0,007)$, and $249 \%+/-70 \%(\mathrm{p}=0,07$, n.s.), respectively; Fig. 4D). 
We conclude from these findings that Chitosan-FPHS implantation is capable of modulating the inflammatory response of injured host tissue by favoring polarization of macrophages towards the beneficial M2 phenotype.

\section{Chitosan-FPHS scaffold enhances restoration of functional vasculature within the} lesion site

Traumatic SCI leads to blood-spinal cord barrier breakdown and vascular network damage, followed by neoangiogenesis (for review, see 43). To determine whether vascular remodeling after SCI is modified in the presence of Chitosan-FPHS scaffold, we examined both pre-existing and newly forming microvasculature by monitoring labeling for SMI71, a marker for mature vessels (Fig. 5), laminin (Fig. 6), and collagen IV (staining basal lamina, BL; Supp. 4). Early angiogenic processes during the first week after injury, including basal lamina deposition by endothelial cells and the formation of basal lamina "streamers" characteristic of neovascularization, were visualized by staining for laminin and collagen IV. In intact (control) animals, as well as in undamaged tissue distant from the primary injury site, all laminin- and collagen IV-positive structures closely colocalized with SMI71 labeling within the same blood vessels, revealing a normal microvasculature and an intact BL (not shown, see 34). In both lesion-only and lesion-Chito animals, the number of SMI71 positive vessels was lower than predicted from the laminin and collagen IV immunoreactivity (compare Fig. 5C with Figs. 6B, and Supp. 4B): laminin-labeled tubes did not always contain endothelial cells, in accordance with previous results $(34,44,45)$. At all time-points analyzed, laminin and collagen IV immunoreactivity was strong at the injury site and in adjacent tissue, identifying the extent of the lesion.

At later time points after the lesion, tissue necrosis in lesion-only animals gave rise to cavity formation, while in the lesion-Chito animals, cells that had invaded the lesion survived, and the newly formed tissue contained mature vasculature as revealed by SMI71 labeling (Fig. 5C). In addition, the Pickworth technique (labeling endogenous peroxidase in erythrocytes; 28) showed that capillaries within the newly formed tissue were perfused, indicative of a functioning vasculature (Fig. 5A,B). Finally, electron microscopy analysis shows that blood vessels in the lesion-Chito implant site exhibit a well-established ultrastructure, and are surrounded by cells resembling pericytes (Fig. 
5D,E; in 5D, also note the presence of an erythrocyte in the vessel lumen).

\section{Chitosan-FPHS implantation leads to coordinated remodeling of cells, extracellular matrix, and axons}

Both in the lesion-only, and lesion-Chito animals, the astroglial scar that delineates the extent of the primary lesion (with the meninges at the lateral edge on horizontal sections; see Fig. 2A,B), is immunoreactive for extracellular matrix (ECM) proteins such as collagen, fibronectin, and laminin. In both experimental conditions, laminin and collagen IV immunostaining revealed the presence of tubular structures that, as mentioned above (see also 34), do not always correspond to newly formed microvessels. Interestingly, the pattern of axons growing through the lesion-Chito implant site corresponded well with that of laminin- and collagen IV-positive tubular structures of varying diameters (Fig. 6, and Supp. 4A,B). In contrast, no clear correlation was observed between axons and fibronectin immunostaining (Supp. 4C,D), which is not surprising since axon adhesion on fibronectin is much weaker than on laminin, as we (and others) have previously shown (46). Fibronectin staining did not exhibit a tubular aspect, and was mainly present at the meningeal limit of the scar, progressively decreasing towards the implant epicenter where it was barely detectable. These observations suggest that axons growing within the implant encounter favorable extracellular matrix components.

Analysis at high magnification showed axons that appeared to colocalize with laminin or collagen IV, were in fact "coated" by tubular structures, suggesting ensheathing by basal lamina expressing cells. This hypothesis was supported by electron microscopy analysis, which revealed axon fascicles enwrapped by basal lamina-coated cellular processes (Figs. 6L and 7B). Moreover, a considerable number of these axons were myelinated by cells exhibiting the ultrastructural features of Schwann cells (i.e. sparse, residual abaxonal cytoplasm immediately adjacent to the myelin sheath, often including the nucleus, and always surrounded by basal lamina; Fig. 7A-C). Tubular structures also contained unmyelinated axons, ensheathed by Schwann cells. Both myelinated and unmyelinated axons coexisted within the same tubule, resembling the ultrastructure of peripheral nerve (29, and see below).

We also performed immunostaining for NG2-proteoglycan, the levels of which are known to increase after SCI. It has been reported that within the first few days after a rat 
dorsal column crush (DCC) injury, dystrophic axons of adult sensory neurons interact with NG2-expressing (NG2+) cells in the vicinity of the lesion (47). After DCC injury in mice, which in contrast to rats do not develop a lesion cavity, such close association of axons and $\mathrm{NG}^{+}$cells appears to persist even at long term (28 days post-injury) within the lesion epicenter, but not with $\mathrm{GFAP}^{+}$astrocytes having formed a wall around the injury site (48). In lesion-only animals we found such an association of NG2+ processes with axons, corroborating the above-cited studies. Moreover, in lesion-Chito animals, a strong association of $\mathrm{NG2}^{+}$cells with axons was also observed within the implant site (Fig. 8A), and the morphology of $\mathrm{NG} 2+^{+}$cells often appeared bipolar and aligned with neighboring axons, resembling radial glia. Since we found axons associated with NG2+ cells within the implant site both at short, and at long term (12 weeks) post-operation, it seems likely that this interaction occurs dynamically during the growth of axons through the Chitosan-FPHS implant site.

The studies cited above also showed that after DCC injury, dystrophic axons might form synapse-like connections on $\mathrm{NG}^{+}$cells. Although we did not investigate this point in detail, we did detect synaptophysin immunostaining along axons having grown through

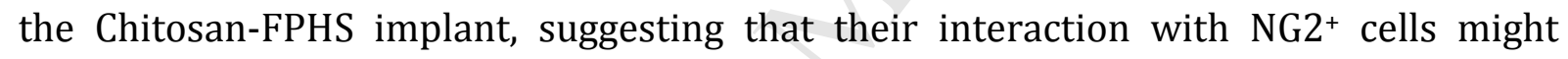
consist of synapse-like connections (Fig. 8B). Finally, some NG2+ cells were also positive for nestin, revealing a neural progenitor cell origin (Fig. 8C-E).

\section{Myelination of axons growing within the Chitosan-FPHS scaffold}

It is well known that during the first weeks after SCI the lesion site is invaded by Schwann cells (SC), which are capable of associating with injured central axons. Normally, however, the number of SC within the lesion site rapidly decreases with time, accompanied by an appearance of axon debris (49). In contrast to lesion-only animals, we found high numbers of SC within the lesion-Chito implant site at 4 weeks and thereafter, identified by labeling for the myelin protein-zero (P0) (Fig. 7E-H). Electron microscopy analysis further revealed that SC had myelinated and ensheathed axons within the tubular structures mentioned above, as well as individual axons within the lesion-Chito implant site (Fig. 7A-C). Electron microscopy also showed the ultrastructure of the implanted Chitosan-FPHS fragments, and as seen in Fig. 7D, at 8 weeks post-operation only Chitosan-FPHS remains were present within the extracellular space, suggesting progressive biodegradation. 
In addition to SC, Olig-2-positive oligodendrocytes were found around the lesion-Chito implant site. Interestingly, penetration of Olig2+ cells into the implant site was limited to the area where astrocyte processes had extended (Fig. 7I-K). Moreover, on adjacent sections, a subpopulation of axons entering the implant displayed strong myelin basic protein (MBP) staining (Fig. 7E and $\mathbf{G}$ ).

\section{Chitosan-FPHS implantation improves locomotor performance after SCI}

All rats showed regular locomotor performance with a maximum BBB score of 21 before injury. A day after SCI, only animals with complete bilateral hind limb paralysis (BBB score $=0$ ) were selected for further behavior analysis, to keep the groups as homogeneous as possible with respect to the severity of the initial lesion. During the first week, little locomotor recovery was observed both for the lesion-only, and the lesion-Chito group of animals. From 2 weeks post-injury onwards, lesion-Chito rats presented higher BBB scores than the lesion-only group, the difference being significant from 3-4 weeks on (score 10 vs. 5, respectively), and up to 10 weeks post-operation, the last time-point evaluated (Fig. 9). Indeed, at 3 weeks post-operation 10\% of lesion-only rats had regained frequent (i.e. intermittent, not permanent) hind limb weight support (BBB score $=11)$, vs. $40 \%$ of lesion-Chito rats. Moreover, at 10 weeks post-operation, lesion-only animals still did not exhibit permanent weight support. In contrast, $100 \%$ of lesion-Chito rats had permanently recovered weight support at 8 weeks after the lesion. Coordination between all four limbs was first observed when the animals reached a BBB score of 12, and became permanent at score =14 (Fig. 9).

Gait analyses via the GaitLab system provide a set of quantitative measurements, focusing on the coordination of legs, and dynamic and static functions of walking. These analyses were performed before the injury, and once a week when animals had regained weight support, i.e. at around 6 weeks after injury for the majority of animals (BBB score 9/10). As most lesion-only rats did not reach permanent weight support with normal locomotion of their forelimbs, we report here only data provided from the lesion-Chito group, by comparing animals to their initial state before the injury. The parameter stride length, corresponding to the distance between two subsequent fore- or hind-paw placements during locomotion, is an indicator of trunk stability of the animal, 
compromised after a dorsal over-hemisection (50). The lesion-Chito group, despite its consistent weight support, exhibited a difference in stride length with their condition before the lesion that remained significant until 6-7 weeks post-lesion. Thereafter, stride length increased until the end of the period analyzed, when animals had almost recovered their initial stride length, both for their hindlimbs (Supp. 5A), and forelimbs (Supp. 5C). Swing time, i.e. the time that the paw is not in contact with the platform, was decreased after injury, but -throughout the study- to a lesser extent (Supp. 5B,D). While it may seem curious that swing time values were consistently different between left and right paws, this is likely explained by the surgical procedure (incision into the spinal tissue) being performed always in the same way by the same person. 


\section{DISCUSSION}

Promising new strategies to treat SCI will involve a combination of approaches, integrating for example cell therapies and/or trophic factor treatment with biomaterialbased scaffolds. The scaffolds serve as neural extracellular matrix substitutes to allow cell adherence, axon outgrowth, and cell survival to repair the damaged tissue. Here, we show that a newly designed formulation, Chitosan-FPHS, in the form of a physical chitosan hydrogel microsuspension is by itself effective in treating SCI, as its implantation into the lesion site immediately after the injury results in a dynamic tissue restorative process, and allows for important axon outgrowth.

Traumatic injury to adult CNS evokes complex cellular responses, including astrocytic scar formation. The scarring is recognized as a major obstacle to CNS repair, because it can both physically and chemically impede axon regrowth. However, astrogliosis is also beneficial in neuronal repair, since astrocytes at the lesion site are essential for neural protection and the regulation of the injury-induced inflammatory response. This is important because efforts to treat SCI by avoiding scar formation through the reduction of expression of selective genes expressed by reactive astrocytes, or by eliminating proliferating astrocytes themselves, appears not suitable as therapeutic approach (for review 51, and refs. therein). In fact, there is direct evidence that scar-forming astrocytes are indispensable for enhancing axon regeneration from adult neurons (52).

The process of glial scar formation after SCI is well documented (53). We showed that in early phases of the formation of the glial scar, astrocytes undergo morphological remodeling in such a way that their processes become oriented towards the injury site, in much the same orientation as growing axons, corroborating our previous report (34). This agrees with other reports on early stages of tissue regeneration in response to initial lesions. In fact, scar tissue formed just after injury produces a number of growthpromoting extracellular matrix (ECM) components, such as fibronectin and laminin, suggesting that at early stages the newly forming scar tissue and astrogliosis supports the functional repair of damaged tissues (54). However, at later times after SCI, factors released from the scarred tissue have a negative impact on tissue repair and recovery (2-4). Astrocytes undergo a second stage of remodeling as a defense response of the 
CNS, intended to minimize damage progression, which results in a dense fibrous network surrounding the cavity that forms at the site of tissue injury.

A major finding of our study is that Chitosan-FPHS implantation prevents formation of a mature scar, facilitating tissue repair by preventing the second stage of astrogliosis, as also reflected by the reduced levels of GFAP expression at the injury site compared to untreated SCI. However, no apparent difference in CSPG immunostaining intensity was found between lesion-Chito and lesion-only conditions. We suggest that the potentially repulsive effect of CSPG (34, and refs. therein) distributed along astrocyte processes might serve to restrain axon branching, or avoid changes in axon growth direction, thus participating in their guidance at the host-implant interface. The inhibitory effect of CSPG could also be "masked" by the presence of high amounts of growth-permissive extracellular matrix components, such as laminin (55), or collagen.

We also analyzed NG2+ glial cells, the contribution of which to scar formation and axon regrowth after SCI is controversially discussed. Although NG2 itself is a potent growthinhibitory proteoglycan $(2,56,57)$, several studies reported a growth-promoting effect of NG2+ glial cells $(47,58,59$, for review 60). Thus, dystrophic axons severed by SCI can become stabilized by the formation of synapse-like connections with NG2+ cells $(47,48)$. This close association can initially prevent axon dieback, but over time it was also suggested to restrain axon extension (48). We observed a tight association of $\mathrm{NG}^{+}$cell processes with axons not only at the lesion-chitosan implant interface, but also along axons growing within the implant site. The overlapping staining patterns for NG2, synaptophysin, and regrowing axons suggest an establishment of synapse-like connections between axons and $\mathrm{NG} 2^{+}$cells. Moreover, these axons do not exhibit branching (as illustrated in Fig. 7A). As suggested above for CSPG, NG2+ cell-axon interactions might have a beneficial effect by preventing the haphazard and aberrant branching of regrowing axons that could impede their efficient circuit reformation and destabilize remaining neural networks $(60,61)$.

A major factor in the efficacy of the Chitosan-FPHS implantation in treating SCI is its local immune-modulatory action. There is a large body of evidence that traumatic CNS injury induces a pronounced microglia/macrophage response. Wound healing generally 
involves an ordered immune response consisting of activation of phenotypically and functionally distinct macrophage subsets. However, this sequence is deregulated after $\mathrm{SCI}$, resulting in a destructive immune reaction $(42,62-65)$. The immune response to SCI initially implies the release of pro-inflammatory cytokines, reactive oxygen species (ROS), and nitric oxide (NO) by "classically activated" M1 macrophages, leading to ECM degradation and clearance of cell debris $(42,66)$. Over time, however, these neurotoxic factors also accelerate glial scar formation, neural cell death and axon retraction (67, 68). Outside the CNS, M1 macrophages are quite rapidly (after about 1 week) replaced by "alternatively activated" macrophage subtypes (M2a, b, c) that successively infiltrate the lesion, where they largely contribute first to tissue repair, then remodeling (also termed "resolution") via release of anti-inflammatory cytokines, stimulation of proliferation of fibroblasts and endothelial cells (angiogenesis), and production of ECM $(65,66)$. In traumatic SCI, this counterbalancing of the destructive actions of M1 macrophages is impaired. M2a macrophages, expressing high levels of arginase-1 and Ym1 (69,70), are activated early, but disappear after about one week post-lesion (as shown in mice; 42), while pro-inflammatory M1 macrophages persist indefinitely. The endogenous events impeding M2 macrophage subtypes to fulfill their role in spinal tissue remodeling have yet to be fully elucidated (65).

Our Western blot and immunohistochemical data let it seem likely that Chitosan-FPHS implantation favors tissue repair in part by increasing activation and/or proliferation of M2 macrophages during the early post-lesion phase (most likely of the M2a subtype, strongly expressing arginase-1). We suggest that the modified inflammatory reaction may in turn be implicated in the recreation of a functional vasculature, which helps to enhance cell survival, and prevent axon retraction and tissue necrosis. This scenario contrasts with untreated SCI, in which the presence of M2 macrophages is rather shortlived (about 1 week; present study, and 42). The in vitro experiments on bone marrowderived macrophage cultures demonstrate that the Chitosan-FPHS itself, when used as substrate, directly influences the expression levels of marker proteins for macrophage polarization, decreasing M1, and increasing M2 markers, respectively. In this respect, it seems interesting to note that implantation of a porous chitosan scaffold in vivo into a mouse skin air pouch model (71) was found to favor adhesion and proliferation of M2, rather than M1 macrophages, if the chitosan had a low DA (5\%), similar to the one used 
in our study (4\%). The inverse result, i.e. predominance of M1 macrophages was observed when the chitosan had a DA of 15\%. Nevertheless, we cannot exclude that the inflammatory response in lesion-Chito animals may also be modulated in a more indirect way, i.e. in consequence to the reduced astrocytic reaction, or via adsorption by the Chitosan-FPHS of pro-inflammatory or toxic factors from the environment (ex.: NO consumption by nitrous deamination of chitosan, see 17). Future studies should clarify how exactly the physico-chemical parameters of the chitosan (namely its DA) influence the inflammatory reaction after SCI, and to which degree chitosan implantation is indeed capable of triggering a tissue-remodeling phase similar to that occurring in normal wound healing by favoring activation of appropriate microglia/macrophage subtypes.

Our study also shows that the Chitosan-FPHS implant favors the invasion and/or enhances the survival of endogenous SC, thereby promoting myelination and ensheathing of regrowing axons, and probably also stimulating axon growth itself. This is important because, although their survival is compromised in untreated SCI $(49,74,75)$, SC are well known to facilitate SCI repair, both transplanted exogenous (72), or endogenous SC invading the lesioned spinal cord. These latter most likely originate from dorsal or ventral roots damaged by the trauma, although other origins have also been proposed, such as CNS-resident glial progenitor cells (73).

Thus, the beneficial effect of Chitosan-FPHS implantation into SCI on tissue and ECM remodeling via modulation of the inflammatory reaction and restoration of a functional vasculature, allows for the creation of an environment supporting important regrowth of both descending, and ascending fibers through the lesion-implant site. Particularly noteworthy appears the fact that the Chitosan-FPHS implant even supports regrowth of the descending corticospinal tract axons, usually thought to have a rather weak regenerative capacity. Finally, this molecular and structural reorganization is not only the basis for spinal tissue reconstitution, but is associated with a significant and longlasting gain in locomotor function recovery when compared to lesion-only animals.

Here, the Chitosan-FPHS was implanted immediately after the injury. Thus, a perspective for a follow-up of the present study is to determine i) the time window during which implantation of the Chitosan-FPHS is effective after the lesion, and ii) 
employ an experimental model more relevant to humans, i.e. a contusion lesion. Determination of this time window is also important when considering application of Chitosan-FPHS into chronic lesions or in combination with other strategies, such as cell therapy, or therapeutic drugs.

To conclude, our data show that the Chitosan-FPHS implantation can repair spinal tissue at least to some degree without being combined with other therapeutic agents. At the same time, it provides major advantages, as it is safe, does not provoke immune reactions in the host tissue, and does not pose any ethical concerns for its use in humans. Chitosan-FPHS can be manufactured as clinical grade material, stored at room temperature, and should not need special facilities or instrumentation for its use on SCI trauma patients. Our study thus provides critical preclinical efficacy data in support of further development of Chitosan-FPHS for treating SCI. 
Author contributions: SS, JC, AM, YvB, LD, and FN designed the experiments; JC, SS, AM, YvB, MVR, MNB, and FN conducted the experiments for biological evaluation and AM, LD for biomaterial preparation and characterization; SS, JC, YvB, CM, JT, FN analyzed experiments; SS, YvB, AM, LD, and FN wrote the manuscript.

\section{Acknowledgements}

We thank J Bouyer from Drexel Univ. for his help with behavior analysis, S Bolt and JF Gilles from IBPS platform, and J Diamant from NPS, and Dr. U Milbreta. We also thank Pr. Marion Murray and Dr. Terry Reisine for careful reading and helpful comments on this manuscript. This work was supported by: Wings for life Foundation (WFL) to FN, Fondation pour la Recherche Médicale (FRM) to LD and FN, FRM/Fondation Wendel to FN and LD, Institut de Recherche sur la Moelle Epinière et l'Encéphale (IRME) to FN, Lyon1-Transfert to LD and FN, CNRS-Pir-AO2010 to FN and LD. We specially thank "Les Amis de la Fondation Wendel" association. 


\section{References}

1. David, S. \& Lacroix, S. Molecular approaches to spinal cord repair. Annu Rev Neurosci 26, 411-440 (2003).

2. Sandvig, A., Berry, M., Barrett, L. B., Butt, A. \& Logan, A. Myelin-, reactive glia-, and scar-derived CNS axon growth inhibitors: expression, receptor signaling, and correlation with axon regeneration. Glia 46, 225-251 (2004).

3. Fawcett, J. W., Schwab, M. E., Montani, L., Brazda, N. \& Muller, H. W. Defeating inhibition of regeneration by scar and myelin components. Handb Clin Neurol 109, 503-522 (2012).

4. Silver, J., Schwab, M. E. \& Popovich, P. G. Central nervous system regenerative failure: role of oligodendrocytes, astrocytes, and microglia. Cold Spring Harb Perspect Biol 7, a020602 (2015).

5. Badylak, S. F., Valentin, J. E., Ravindra, A. K., McCabe, G. P. \& Stewart-Akers, A. M. Macrophage phenotype as a determinant of biologic scaffold remodeling. Tissue Eng Part A 14, 1835-1842 (2008).

6. Brown, B. N. et al. Macrophage phenotype as a predictor of constructive remodeling following the implantation of biologically derived surgical mesh materials. Acta Biomater 8, 978-987 (2012).

7. Hurtado, A. et al. Robust CNS regeneration after complete spinal cord transection using aligned poly-L-lactic acid microfibers. Biomaterials 32, 6068-6079 (2011).

8. Nomura, H., Katayama, Y., Shoichet, M. S. \& Tator, C. H. Complete spinal cord transection treated by implantation of a reinforced synthetic hydrogel channel results in syringomyelia and caudal migration of the rostral stump. Neurosurgery 59, 183-92; discussion 183 (2006).

9. Estrada, V. et al. Long-lasting significant functional improvement in chronic severe spinal cord injury following scar resection and polyethylene glycol implantation. Neurobiol Dis 67, 165-179 (2014).

10. Lu, P. et al. Long-distance growth and connectivity of neural stem cells after severe spinal cord injury. Cell 150, 1264-1273 (2012).

11. Novikova, L. N. et al. Alginate hydrogel and matrigel as potential cell carriers for neurotransplantation. J Biomed Mater Res A 77, 242-252 (2006).

12. Kim, H., Tator, C. H. \& Shoichet, M. S. Chitosan implants in the rat spinal cord: biocompatibility and biodegradation. J Biomed Mater Res A 97, 395-404 (2011).

13. Gnavi, S. et al. The use of chitosan-based scaffolds to enhance regeneration in the nervous system. Int Rev Neurobiol 109, 1-62 (2013).

14. Pego, A. P. et al. Regenerative medicine for the treatment of spinal cord injury: more than just promises? J Cell Mol Med 16, 2564-2582 (2012).

15. Yang, T. L. Chitin-based materials in tissue engineering: applications in soft tissue and epithelial organ. Int J Mol Sci 12, 1936-1963 (2011).

16. Montembault, A. et al. A material decoy of biological media based on chitosan physical hydrogels: application to cartilage tissue engineering. Biochimie 88, 551564 (2006).

17. Ladet, S. G., Tahiri, K., Montembault, A. S., Domard, A. J. \& Corvol, M. T. Multimembrane chitosan hydrogels as chondrocytic cell bioreactors. Biomaterials 32, 5354-5364 (2011).

18. Li, X., Yang, Z., Zhang, A., Wang, T. \& Chen, W. Repair of thoracic spinal cord injury by chitosan tube implantation in adult rats. Biomaterials 30, 1121-1132 (2009).

19. Bozkurt, G. et al. Chitosan channels containing spinal cord-derived 
stem/progenitor cells for repair of subacute spinal cord injury in the rat. Neurosurgery 67, 1733-1744 (2010).

20. Yang, Z. et al. NT3-chitosan elicits robust endogenous neurogenesis to enable functional recovery after spinal cord injury. Proc Natl Acad Sci U S A 112, 1335413359 (2015).

21. Zhang, J. et al. Chitosan scaffolds induce human dental pulp stem cells to neural differentiation: potential roles for spinal cord injury therapy. Cell Tissue Res (2016).

22. Montembault A, Viton C, Domard A, rheometric study of gelation of chitosan in aqueous solutions without crosslinking agent, Biomacromolecules 6, 653-662 (2005).

23. Hirai A, Odani H, Nakajima A, Determination of degree of deacetylation of chitosan by 1H NMR spectroscopy, Polymer Bulletin, 126, 87-94 (1991).

24. Fiamingo A, Montembault A, Boitard SE, Naemetalla H, Agbulut O, Delair T, Campana-Filho SP, Menasché P, David L Chitosan Hydrogels for the Regeneration of Infarcted Myocardium: Preparation, Physicochemical Characterization, and Biological Evaluation. Biomacromolecules 17(5):1662-72 (2016).

25. Nothias, F., Soares, S., David, L., \& Montembault, A. Chitosan hydrogel for repairing nerve tissue; EP2874672 (B1), (2016).

26. Sharp KG, Dickson AR, Marchenko SA, Yee KM, Emery PN, Laidmåe I, Uibo R, Sawyer ES, Steward O, Flanagan LA (2012) Salmon fibrin treatment of spinal cord injury promotes functional recovery and density of serotonergic innervation. Experimental neurology, 235:345-356.

27. Fouquet, $\mathrm{C}$. et al. Improving axial resolution in confocal microscopy with new high refractive index mounting media. PLoS One 10, e0121096 (2015).

28. Pickworth, F. A. A New Method of Study of the Brain Capillaries and its Application to the Regional Localisation of Mental Disorder.J Anat 69, 62-71 (1934).

29. von Boxberg, Y. et al. Giant scaffolding protein AHNAK1 interacts with betadystroglycan and controls motility and mechanical properties of Schwann cells. Glia 62, 1392-1406 (2014).

30. Boxberg, Y. V. Protein analysis on two-dimensional polyacrylamide gels in the femtogram range: use of a new sulfur-labeling reagent. Anal Biochem 169, 372-375 (1988).

31. Zhang, X., Goncalves, R. \& Mosser, D. M. The isolation and characterization of murine macrophages. Curr Protoc Immunol Chapter 14, Unit 14.1 (2008).

32. Basso, D. M., Beattie, M. S.\& Bresnahan, J. C. A sensitive and reliable locomotor rating scale for open field testing in rats. J Neurotrauma 12, 1-21 (1995).

33. Hamers, F. P., Koopmans, G. C. \& Joosten, E. A. CatWalk-assisted gait analysis in the assessment of spinal cord injury. J Neurotrauma 23, 537-548 (2006).

34. Milbreta, U., von Boxberg, Y., Mailly, P., Nothias, F. \& Soares, S. Astrocytic and Vascular Remodeling in the Injured Adult Rat Spinal Cord after Chondroitinase ABC Treatment. J Neurotrauma 31, 803-818 (2014).

35. Soares, S. et al. Extensive structural remodeling of the injured spinal cord revealed by phosphorylated MAP1B in sprouting axons and degenerating neurons. Eur J Neurosci 26, 1446-1461 (2007).

36. Ren, Y. \& Young, W. Managing inflammation after spinal cord injury through manipulation of macrophage function. Neural Plast 2013, 945034 (2013).

37. Bastien, D. \& Lacroix, S. Cytokine pathways regulating glial and leukocyte function after spinal cord and peripheral nerve injury. Exp Neurol 258, 62-77 (2014). 
38. Donnelly, D. J. \& Popovich, P. G. Inflammation and its role in neuroprotection, axonal regeneration and functional recovery after spinal cord injury. Exp Neurol 209, 378-388 (2008).

39. Hawthorne, A. L. \& Popovich, P. G. Emerging concepts in myeloid cell biology after spinal cord injury. Neurotherapeutics 8, 252-261 (2011).

40. Stout, R. D. \& Suttles, J. Functional plasticity of macrophages: reversible adaptation to changing microenvironments. J Leukoc Biol 76, 509-513 (2004).

41. Menzies, F. M., Henriquez, F. L., Alexander, J. \& Roberts, C. W. Sequential expression of macrophage anti-microbial/inflammatory and wound healing markers following innate, alternative and classical activation. Clin Exp Immunol 160, 369-379 (2010).

42. Kigerl, K. A. et al. Identification of two distinct macrophage subsets with divergent effects causing either neurotoxicity or regeneration in the injured mouse spinal cord. J Neurosci 29, 13435-13444 (2009).

43. Oudega, M. Molecular and cellular mechanisms underlying the role of blood vessels in spinal cord injury and repair. Cell Tissue Res 349, 269-288 (2012).

44. Benton, R. L., Maddie, M. A., Minnillo, D. R., Hagg, T. \& Whittemore, S. R. Griffonia simplicifolia isolectin B4 identifies a specific subpopulation of angiogenic blood vessels following contusive spinal cord injury in the adult mouse. J Comp Neurol 507, 1031-1052 (2008).

45. Loy, D. N. et al. Temporal progression of angiogenesis and basal lamina deposition after contusive spinal cord injury in the adult rat. J Comp Neurol 445, 308-324 (2002).

46. Fereol, S. et al. Micropatterned ECM substrates reveal complementary contribution of low and high affinity ligands to neurite outgrowth. Cytoskeleton (Hoboken) 68, 373-388 (2011).

47. Busch, S. A. et al. Adult NG2+ cells are permissive to neurite outgrowth and stabilize sensory axons during macrophage-induced axonal dieback after spinal cord injury. J Neurosci 30, 255-265 (2010).

48. Filous, A. R. et al. Entrapment via synaptic-like connections between NG2 proteoglycan + cells and dystrophic axons in the lesion plays a role in regeneration failure after spinal cord injury. J Neurosci 34, 16369-16384 (2014).

49. Brook, G. A. et al. Spontaneous longitudinally orientated axonal regeneration is associated with the Schwann cell framework within the lesion site following spinal cord compression injury of the rat. J Neurosci Res 53, 51-65 (1998).

50. Hamers, F. P., Lankhorst, A. J., van Laar, T. J., Veldhuis, W. B. \& Gispen, W. H. Automated quantitative gait analysis during overground locomotion in the rat: its application to spinal cord contusion and transection injuries. J Neurotrauma 18, 187-201 (2001).

51. Sofroniew, M. V. Molecular dissection of reactive astrogliosis and glial scar formation. Trends in Neurosciences 32, 638-647 (2009).

52. Anderson, M. A. et al. Astrocyte scar formation aids central nervous system axon regeneration. Nature 532, 195-200 (2016).

53. Wanner, I. B. et al. Glial Scar Borders Are Formed by Newly Proliferated, Elongated Astrocytes That Interact to Corral Inflammatory and Fibrotic Cells via STAT3Dependent Mechanisms after Spinal Cord Injury. J Neurosci 33, 12870-12886 (2013).

54. Silver, J. \& Miller, J. H. Regeneration beyond the glial scar. Nat Rev Neurosci 5, 146156 (2004). 
55. Yuan XB, Jin Y, Haas C, Yao L, Hayakawa K, Wang Y, Wang C,Fischer I (2016) Guiding migration of transplanted glial progenitor cells in the injured spinal cord. Sci Rep, 6:22576.

56. Shearer, M. C. et al. The astrocyte/meningeal cell interface is a barrier to neurite outgrowth which can be overcome by manipulation of inhibitory molecules or axonal signalling pathways. Mol Cell Neurosci 24, 913-925 (2003).

57. Tang, X., Davies, J. E. \& Davies, S. J. Changes in distribution, cell associations, and protein expression levels of NG2, neurocan, phosphacan, brevican, versican V2, and tenascin-C during acute to chronic maturation of spinal cord scar tissue. J Neurosci Res 71, 427-444 (2003).

58. Jones, L. L., Sajed, D. \& Tuszynski, M. H. Axonal regeneration through regions of chondroitin sulfate proteoglycan deposition after spinal cord injury: a balance of permissiveness and inhibition. J Neurosci 23, 9276-9288 (2003).

59. McTigue, D. M., Tripathi, R. \& Wei, P. NG2 colocalizes with axons and is expressed by a mixed cell population in spinal cord lesions. J Neuropathol Exp Neurol 65, 406420 (2006).

60. Mangin, J. M. \& Gallo, V. The curious case of NG2 cells: transient trend or game changer? ASN Neuro 3, e00052 (2011).

61. Harel, N. Y. \& Strittmatter, S. M. Can regenerating axons recapitulate developmental guidance during recovery from spinal cord injury? Nat Rev Neurosci 7, 603-616 (2006).

62. David, S. \& Kroner, A. Repertoire of microglial and macrophage responses after spinal cord injury. Nat Rev Neurosci 12, 388-399 (2011).

63. Shechter, R. \& Schwartz, M. Harnessing monocyte-derived macrophages to control central nervous system pathologies: no longer 'if' but 'how'. J Pathol 229, 332-346 (2013).

64. Shin, T., Ahn, M., Moon, C., Kim, S. \& Sim, K. B. Alternatively activated macrophages in spinal cord injury and remission: another mechanism for repair? Mol Neurobiol 47, 1011-1019 (2013).

65. Gensel, J. C. \& Zhang, B. Macrophage activation and its role in repair and pathology after spinal cord injury. Brain Res 1619, 1-11 (2015).

66. Wermuth, P. J. \& Jimenez, S. A. The significance of macrophage polarization subtypes for animal models of tissue fibrosis and human fibrotic diseases. Clin Transl Med 4, 2 (2015).

67. Fitch, M. T., Doller, C., Combs, C. K., Landreth, G. E. \& Silver, J. Cellular and molecular mechanisms of glial scarring and progressive cavitation: in vivo and in vitro analysis of inflammation-induced secondary injury after CNS trauma. J Neurosci 19, 8182-8198 (1999).

68. Horn, K. P., Busch, S. A., Hawthorne, A. L., van Rooijen, N. \& Silver, J. Another barrier to regeneration in the CNS: activated macrophages induce extensive retraction of dystrophic axons through direct physical interactions. J Neurosci 28, 9330-9341 (2008).

69. Mosser, D. M. \& Edwards, J. P. Exploring the full spectrum of macrophage activation. Nat Rev Immunol 8, 958-969 (2008).

70. Daley, J. M., Brancato, S. K., Thomay, A. A., Reichner, J. S. \& Albina, J. E. The phenotype of murine wound macrophages. J Leukoc Biol 87, 59-67 (2010).

71. Vasconcelos, D. P. et al. Macrophage polarization following chitosan implantation. Biomaterials 34, 9952-9959 (2013). 
72. Blight, A. R. \& Young, W. Central axons in injured cat spinal cord recover electrophysiological function following remyelination by Schwann cells. J Neurol Sci 91, 15-34 (1989).

73. Zawadzka, M. et al. CNS-resident glial progenitor/stem cells produce Schwann cells as well as oligodendrocytes during repair of CNS demyelination. Cell Stem Cell 6, 578-590 (2010).

74. Oudega, M. \& Xu, X. M. Schwann cell transplantation for repair of the adult spinal cord. J Neurotrauma 23, 453-467 (2006).

75. Bunge, M. B. \& Wood, P. M. Realizing the maximum potential of Schwann cells to promote recovery from spinal cord injury. Handb Clin Neurol 109, 523-540 (2012). 
Figure legends:

Figure 1- (A) Preparation of Chitosan-FPHS, from chitosan powder up to the microhydrogel suspension for injection into the spinal cord, as described in Materials and Methods. Phase contrast images (to the right) correspond to Chitosan-FPHS with a DA of $4 \%$, but different median fragment sizes: top, about $150 \mu \mathrm{m}$; bottom, about $20 \mu \mathrm{m}$. The latter fragment size was selected for the present study. Bar: left, $1 \mathrm{~cm}$; right, $100 \mu \mathrm{m}$. (B) Apparent viscosity in relation to apparent shear rate of Chitosan-FPHS with a DA of $4 \%$ and obtained after fragmentation with an Ultra Turrax ${ }^{\circledR}$ (IKA) homogenizer (rotation speed $11000 \mathrm{rpm}, 4$ x $20 \mathrm{sec}$, median fragment size $20 \mu \mathrm{m}$ ) and centrifugation with Sigma 3K30 at $13000 \mathrm{rpm}$ during $3 \mathrm{~min}$. The rheological characterization was performed using a stress-controlled rheometer (AR 2000, TA instruments) at $22^{\circ} \mathrm{C}$. The apparent viscosity was assessed in static mode using cone/plate geometry $(25 \mathrm{~mm}$ diameter, $4^{\circ}$ cone angle).

Figure 2- Chitosan-FPHS implantation leads to reduced astrocytic reaction and robust axon regrowth:

Immunohistochemical labeling of sections through the spinal cord lesion site for astrocytes (GFAP, green), axons (either NF [SMI31-32], red, for neurofilaments; or Tuj1 for betaIII-tubulin, red), and cell nuclei (Dapi, blue), 4 weeks after lesion only (A) or lesion followed by Chitosan-FPHS implantation (B-H). (G, H) Association of axons with astrocyte $\left(\mathrm{GFAP}^{+}\right)$processes at the zone of axon (Tuj $\left.1^{+}\right)$entry into the lesion-Chito implant site, (G) confocal image, and (H) 3D representation after deconvolution and Volocity treatment of a confocal image of a section adjacent to G. (I) Quantification representing the relative density of NF/SMI31-32 immunostained fibers within the lesion-only (Lesion), or lesion-Chito implant site (Lesion-Chito) 2, 4, and 10 weeks after surgery, showing the robust axon regrowth promoted and maintained in presence of the Chitosan-FPHS, significantly more important than in lesion-only animals at 4 weeks post-lesion; in lesion-only animals, while some fibers are growing in the lesion site during the first weeks, at 10 weeks post-lesion the lesion site is completely devoid of fibers because of cavity formation ${ }^{* * * *} \mathrm{p}<0,0001$; one-way Anova analysis with Tukey's test; $\mathrm{n}=3$ per group of animals ( $>3$ sections per animal). (J) Representative Western blot of spinal cord protein extracts stained for GFAP (with actin staining used for 
normalization) 4 days, 1, 4, and 8 weeks after lesion only (Chito -), or lesion followed by Chitosan-FPHS implant (Chito+). Quantification shows no difference between the two conditions during the first 4 weeks, while relative GFAP levels significantly increase in the lesion-only group towards 8 weeks post-operation. ${ }^{*} \mathrm{p}=0,0282$ (One-way Anova analysis with Dunnett's test). (K) The average cystic cavity surfaces of lesion-only, and lesion-Chito animals are significantly different; $\mathrm{n}=3$ per group of animals $(>3$ sections per animal); t-test, ${ }^{* * * *}$ p <0.001). Scale bars, A,B $240 \mu \mathrm{m}$; C-F $190 \mu \mathrm{m} ; \mathrm{G}, 125 \mu \mathrm{m} ; \mathrm{H}, 90$ $\mu \mathrm{m}$.

\section{Figure 3- Chitosan-FPHS leads to axon regrowth from different origins:}

(A-C) BDA tracing (Strept, green) of corticospinal fibers, representative images taken at the caudal (A) and rostral (C) interfaces between intact and lesion-Chito implant tissue, and within the lesion-Chito implant itself (B), 11 weeks post-operation. (D-I) Primary sensory afferents 10 weeks post-lesion revealed in (D-F) by CTB (red) axon tracing of myelinated fibers from the sciatic nerve (note some labeled dorsal column (DC) fibers within the lesion-implant tissue [inset]), and in (G-I) by CGRP (red) immunostaining expressed on fibers from small-unmyelinated to medium size-myelinated dorsal root ganglia neurons. (J-0) Supraspinal descending 5HT-immunostained fibers within the lesion-implant site (J-L), and in the ventro-caudal region underneath the primary lesion (M-0), 16 weeks post-lesion. Tuj1 (green) was used to reveal all fibers entering the lesion-implant site and nuclear Dapi staining (blue) for cells that occupy this area. The inset in $\mathrm{C}$ is an illustration of the above-cited orientations on a horizontal spinal cord section: $\mathrm{C}$, caudal ; R, rostral; 1 , caudal interface between host and lesion-Chito implant site; 2 , lesion-Chito implant site; 3 , rostral interface between host tissue and lesion-Chito implant site. Scale bars, A-C $126 \mu \mathrm{m}$; D-O $140 \mu \mathrm{m}$.

\section{Figure 4- Modulation of the inflammatory response by Chitosan-FPHS:}

(A) Western blots of spinal cord protein extracts, 4 days, and 1, 4, and 8 weeks after lesion only (Chito -) or lesion followed by Chitosan-FPHS implant (Chito +) stained for M2 (CD206 and Arg-1), M1 (CD86), and pan-macrophage (CD68) marker proteins, as well as actin and GADPH; (B) Western blot of the same samples used in (A) stained for total protein content with colloidal gold; (C) quantification of relative amounts of each macrophage marker. While pan-macrophage staining shows no difference between the 
two animal groups, Chitosan-FPHS implantation leads to a significant transient increase in M2 marker protein Arg-1 at one week, as well as an increase in CD206 levels from 4 weeks post-lesion. ${ }^{*} \mathrm{p}=0,0286$ for CD86; * $\mathrm{p}=0,0407$ for CD206; ** $\mathrm{p}=0,0035$; **** $\mathrm{p}<0,00010.05$, one-way Anova analysis with Tukey's test. (D) Western blots of protein extracts from mouse bone marrow macrophage cultures grown on tissue culture plastic $(-)$, or on Chitosan-FPHS substrate $(+)$, respectively, and polarized during $24 \mathrm{~h}$ towards the M1, or the M2 phenotype ("M0", negative control without any polarizing treatment).

Figure 5- Restoration of functional vasculature within the lesion-Chitosan-FPHS implant site:

(A-B) Angio-architectony at 10 weeks post-operation, functional vasculature revealed via the Pickworth technique; $\mathbf{B}$ is a higher magnification of $\mathbf{A}$ at the level of lesion-Chito implant site indicated by a star. (C) Representative SMI71 immunohistochemistry showing mature blood vessels within the lesion-Chito implant site, 10 weeks postoperation. (D-E) Electron microscopy images of the lesion-implant site at 8 weeks postoperation, showing the blood vessel ultrastructure (Lu, lumen; Er, erythrocyte). Scale bars, A, $500 \mu \mathrm{m} ; \mathrm{B}, 250 \mu \mathrm{m} ; \mathrm{C}, 300 \mu \mathrm{m}$.

Figure 6- Association of axon network with laminin within lesion-Chitosan-FPHS implant site:

(A-K) Representative immunohistochemistry images showing a strong correlation of the distribution of axons (NF, red in merge images) with that of laminin (LN, green in merge images) within the lesion-Chitosan-FPHS implant site. (E-K) High magnification shows axons colocalizing with laminin-positive tubular structures, suggesting ensheathing by basal lamina-producing cells. Nuclear Dapi staining (blue) is added in merge image in $\mathbf{K}$. (L) Electron microscopy image showing a tubule containing axons that are myelinated, or ensheathed-unmyelinated by Schwann cells. A-D, 10 weeks, E-K, 6 weeks, L, 8 weeks post-operation. Scale bars, A-D $150 \mu \mathrm{m} ; \mathrm{F}-\mathrm{H} 80 \mu \mathrm{m}$.

\section{Figure 7- Myelination of axons within the lesion-Chitosan-FPHS implant site:}

(A-C) Representative electron microscope images of axons in the lesion-Chitosan-FPHS implant site that are myelinated by Schwann cells, 8 weeks post-operation. (A) Ranvier node (between the two arrowheads; the arrow points to the basal lamina); (B) tubular 
structure containing a group of both myelinated, and unmyelinated-ensheathed axons; (C) individual myelinated, and unmyelinated-ensheathed axons. (D) Ultrastructure of Chitosan-FPHS residues (asterisks) within the extracellular space, 8 weeks postoperation. (E-H) Myelinated axons 10 weeks post-lesion within the lesion-ChitosanFPHS implant site, immunolabeled for $\operatorname{MBP}(\mathbf{E}, \mathbf{G})$, and P0 (F,H). P0 reflects the distribution of Schwann cells and their myelin throughout the lesion-Chitosan-FPHS implant site. (I-K) Representative double immunohistochemistry for GFAP and Olig2 (oligodendrocyte-specific transcription factor), showing the presence of numerous oligodendrocytes at the host-implant interface, whose migration into the implant site appears limited to the region covered by astrocyte processes; 4 weeks post-lesion. Scale bars, E,F $127 \mu \mathrm{m} ; \mathrm{G}, \mathrm{H} 38 \mu \mathrm{m}$; I-K $157 \mu \mathrm{m}$.

Figure 8- Association between the axon network and NG2-positive cells in the lesion-Chitosan-FPHS implant site:

Representative immunohistochemistry illustrating a correlation between the distribution of axons (Tuj1+) and NG2+ cells (arrows) and their processes (A), as well as with that of synaptophysin (B), 10 weeks post-operation. (C-E) Double immunostaining for nestin and NG2, 8 weeks post-operation. Some $\mathrm{NG} 2+^{+}$cells also express nestin (arrowheads), suggesting their origin from nestin-positive immature, proliferating cells. Scale bars, A and B, $48 \mu \mathrm{m}$; C-E $97 \mu \mathrm{m}$.

\section{Figure 9- Chitosan-FPHS implantation leads to improvement in locomotor function:}

Open-field locomotion of rats having received a spinal cord dorsal hemisection with (lesion-Chito), or without (lesion-only) Chitosan-FPHS implantation was evaluated according to the standard Basso-Beattie-Bresnahan (BBB) locomotor scale. Before injury, all animals had BBB score=21. A day after the injury, only animals with complete bilateral hind limb paralysis (BBB score $=0$ ) were selected for further analysis. During the first week, little locomotor recovery was observed both for the lesion-only and the lesion-Chito group of animals. From 2 weeks post-injury onwards, lesion-Chito rats presented higher BBB scores than the lesion-only group, the difference being significant from 3-4 weeks on. ${ }^{*} \mathrm{p}=0,0014$ for $5 \mathrm{~W}$ and ${ }^{* *} \mathrm{p}=0,0046$ for $8 \mathrm{~W} ;{ }^{* * *} \mathrm{p}=0,0001$ for $3 \mathrm{~W}$ and 
*** $\mathrm{p}=0,007$ for $7 \mathrm{~W} ;{ }^{* * * *} \mathrm{p}<0,0001$ (2-way Anova analysis with Sidak's test; $\mathrm{n}=10$ for each group).

\section{Supplemental material:}

\section{Supplemental figure 1 (Supp. 1) - Influence of particle size and DA of Chitosan-} FPHS. Horizontal sections of lesioned rat spinal cord implanted with two different formulations of Chitosan-FPHS in terms of DA and particle size, 4 weeks post-injury. A: immunofluorescence staining for GFAP (astrocytes, green) and neurofilaments (fibers, red) shows that after implantation of Chitosan-FPHS with large particle size $(\sim 150 \mu \mathrm{m})$ only few axons are noted within the lesion-implant site, where large size chitosan fragments (red auto-fluorescence) are observed. B: ED1 (macrophages, green) and laminin (red) staining showing that a high DA (38\%) Chitosan-FPHS leads to a nonvascularized necrotic tissue. Scale bar, $300 \mu \mathrm{m}$.

\section{Supplemental figure 2 (Supp. 2) - CSPG is detected in both lesion-only and lesion-} Chito spinal cord. Confocal images of double immunofluorescence of GFAP (A,D,G; green in merge images C,F,I) with CSPG (CS-56 antibody; B,H; red in merge images C,I), or with betaIII-tubulin (Tuj1 antibody, E; red in merge image F), in lesion-only (A-C) and in lesion-Chito (D-I) spinal cord horizontal sections. D-F is a section adjacent to G-I, showing the superposition of GFAP staining with beta-3 tubulin and CSPG in the same fibrillar structures. Scale bar, $90 \mu \mathrm{m}$.

\section{Supplemental figure 3 (Supp. 3) - Increased presence of M2-polarized anti-} inflammatory macrophages at the lesion-Chitosan-FPHS implant site. Immunohistochemical labeling of the lesion site for macrophage marker proteins ED1 (phagocytic macrophages/microglia), CD86 (M1 macrophages), and CD206 (M2 macrophages). (A-E) 2weeks and (H,I) 10 weeks post-lesion with Chitosan-FPHS implantation, and $(\mathbf{F}, \mathbf{G}) 10$ weeks after lesion-only; $\mathbf{C}$ and $\mathbf{D}$ are higher magnifications of insets in $\mathbf{A}$, at the border of, and within the implant site, respectively; $\mathbf{E}$ is a higher magnification of inset in B. Scale bars, A,B $300 \mu \mathrm{m}$; C-E $30 \mu \mathrm{m}$; F-I $100 \mu \mathrm{m}$. 
Supplemental figure 4 (Supp. 4) - Association of axon network with collagen-IV, but not fibronectin, within the lesion-Chitosan-FPHS implant site.

Immunohistochemistry showing a strong correlation between the distribution of axons (Tuj1, green) and that of collagen-IV (red, arrows, Coll IV, A, B), but not fibronectin (red, asterisks; FN, C, D) within the lesion-Chitosan-FPHS implant site at 11 weeks postoperation at low (A, C), and high magnification (B,D). Nuclear Dapi staining is in blue. Scale bars, A,C $100 \mu \mathrm{m}$; B,D $30 \mu \mathrm{m}$.

\section{Supplemental figure 5 (Supp. 5) - Gait analyses for Chitosan-FPHS implanted} animals. GaitLab system analyses were performed before the injury then once a week when animals had regained weight support, i.e. at around 6 weeks after operation (BBB score 9/10, n=7). Stride length (A,C), and swing time (B,D) are indicators of trunk stability of the animal, compromised after a dorsal hemisection. One-way Anova with Dunett's test was performed to compare injured (WPL, weeks post lesion) with uninjured data (D-1, i.e. day before lesion). Note that animals have regained almost normal (pre-lesion) values for both parameters from 8 weeks onwards; at 7W, a significant decrease of stride length is still observed for the right forelimb $(* p=0,0324)$, and swing times are significantly shorter at $6 \mathrm{~W}$ for the right forelimb $\left({ }^{*} \mathrm{p}=0,014\right)$, at $7 \mathrm{~W}$ for the right hindlimb $(* p=0,0139)$. 

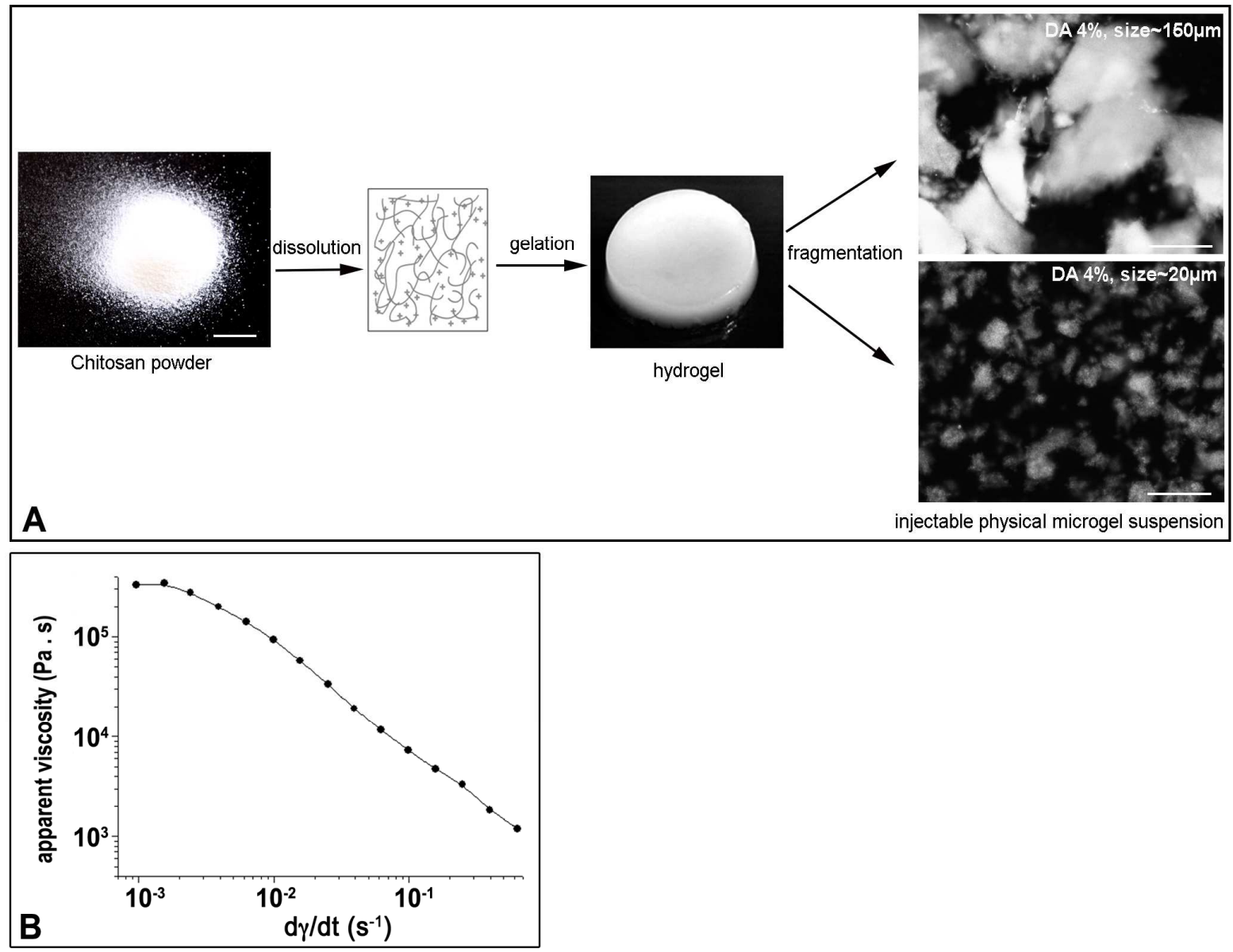


\section{ACCEPTED MANUSCRIPT}
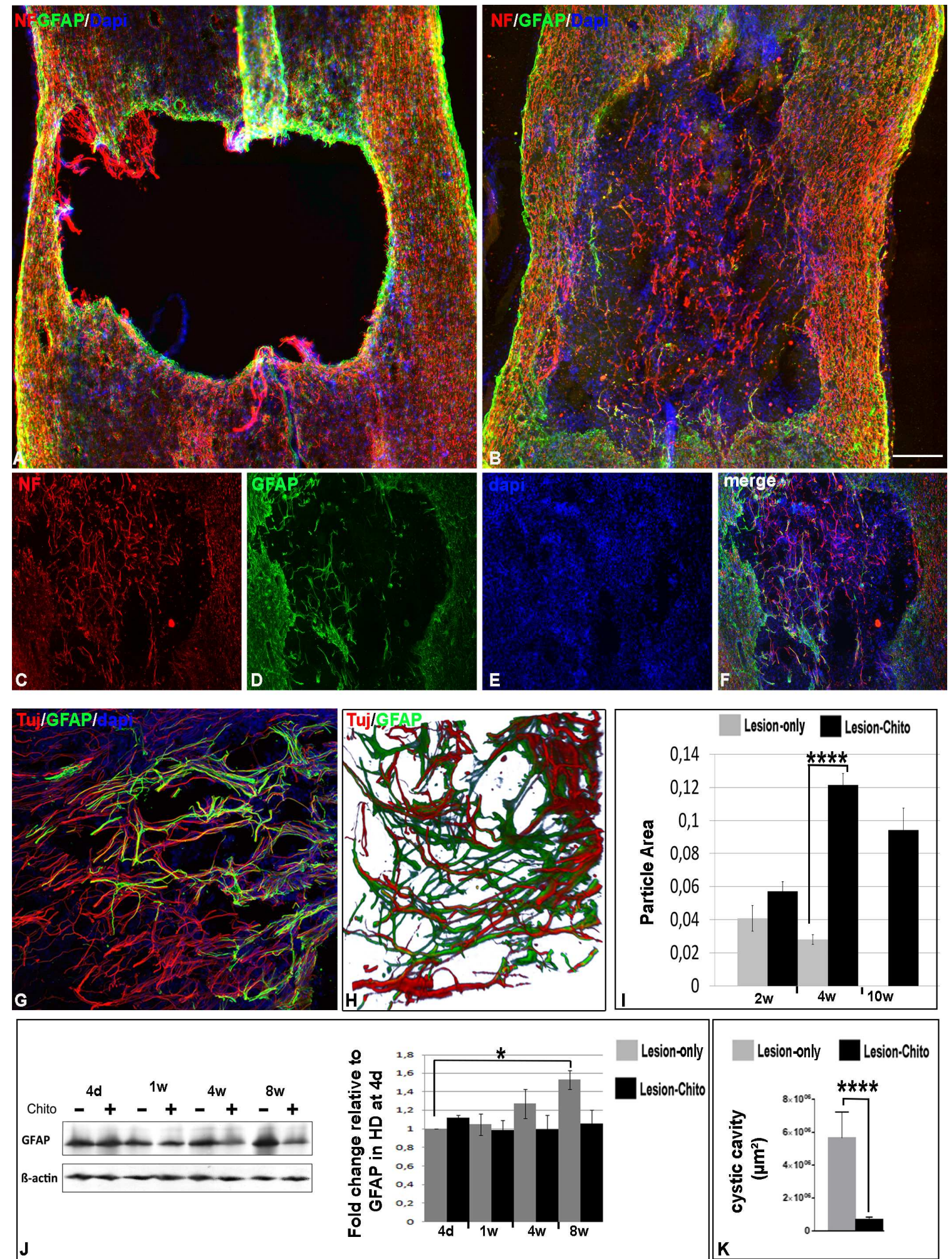

Lesion-only Lesion-only

Lesion-Chito
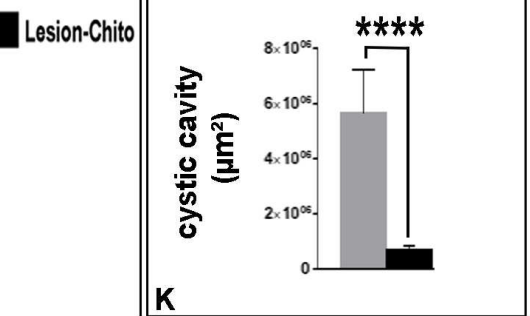


\section{ACCEPTED MANUSCRIPT}

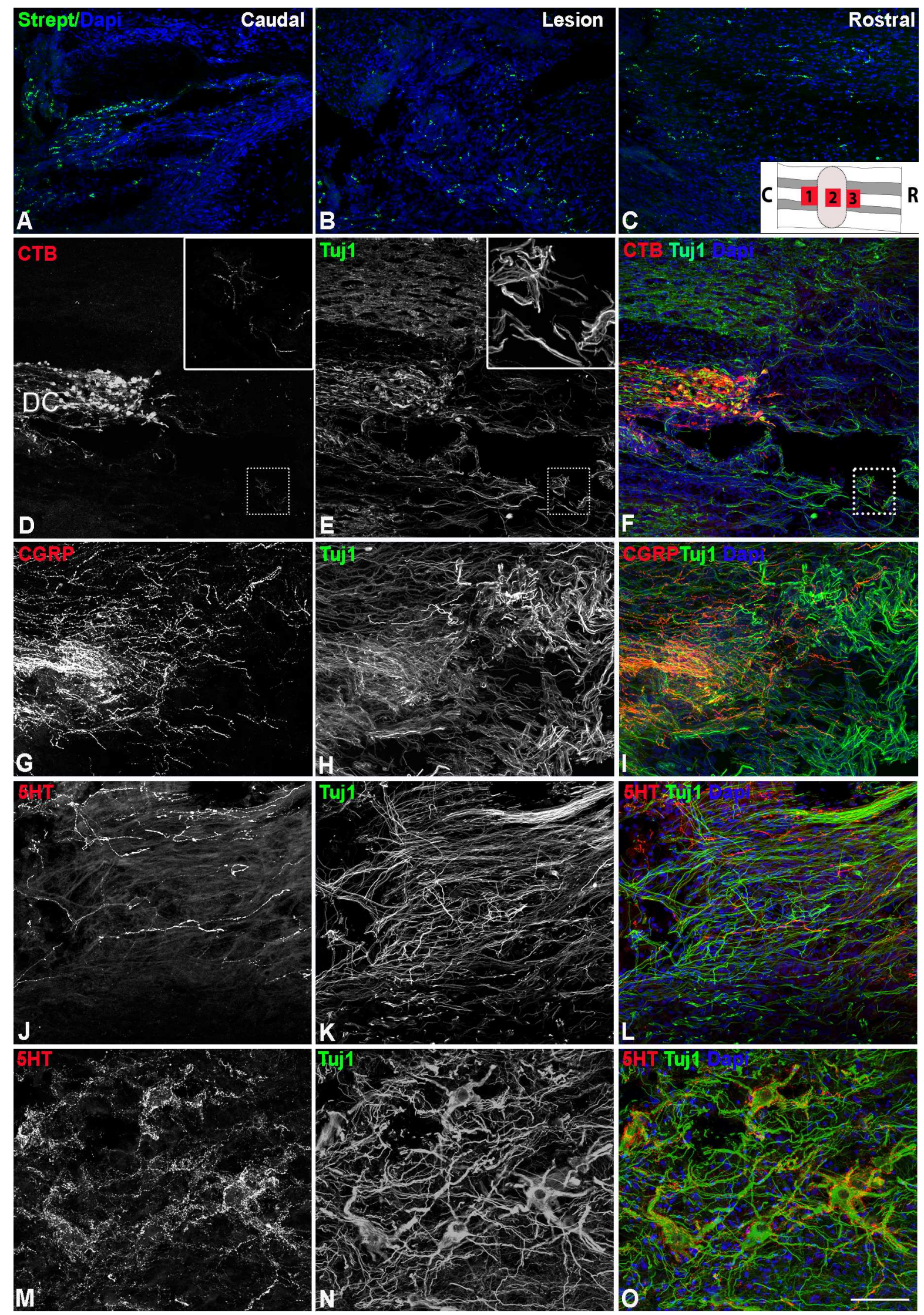




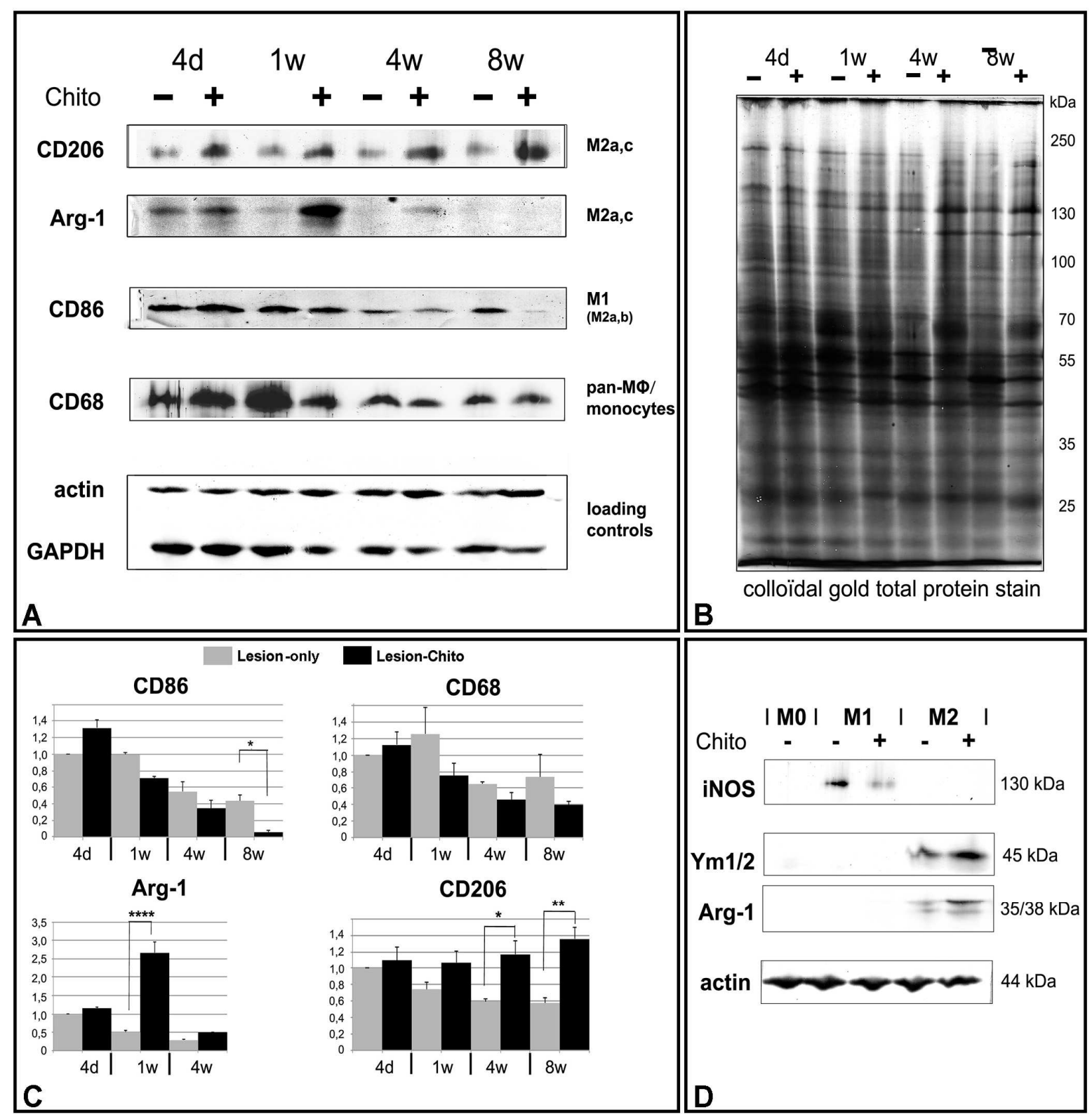



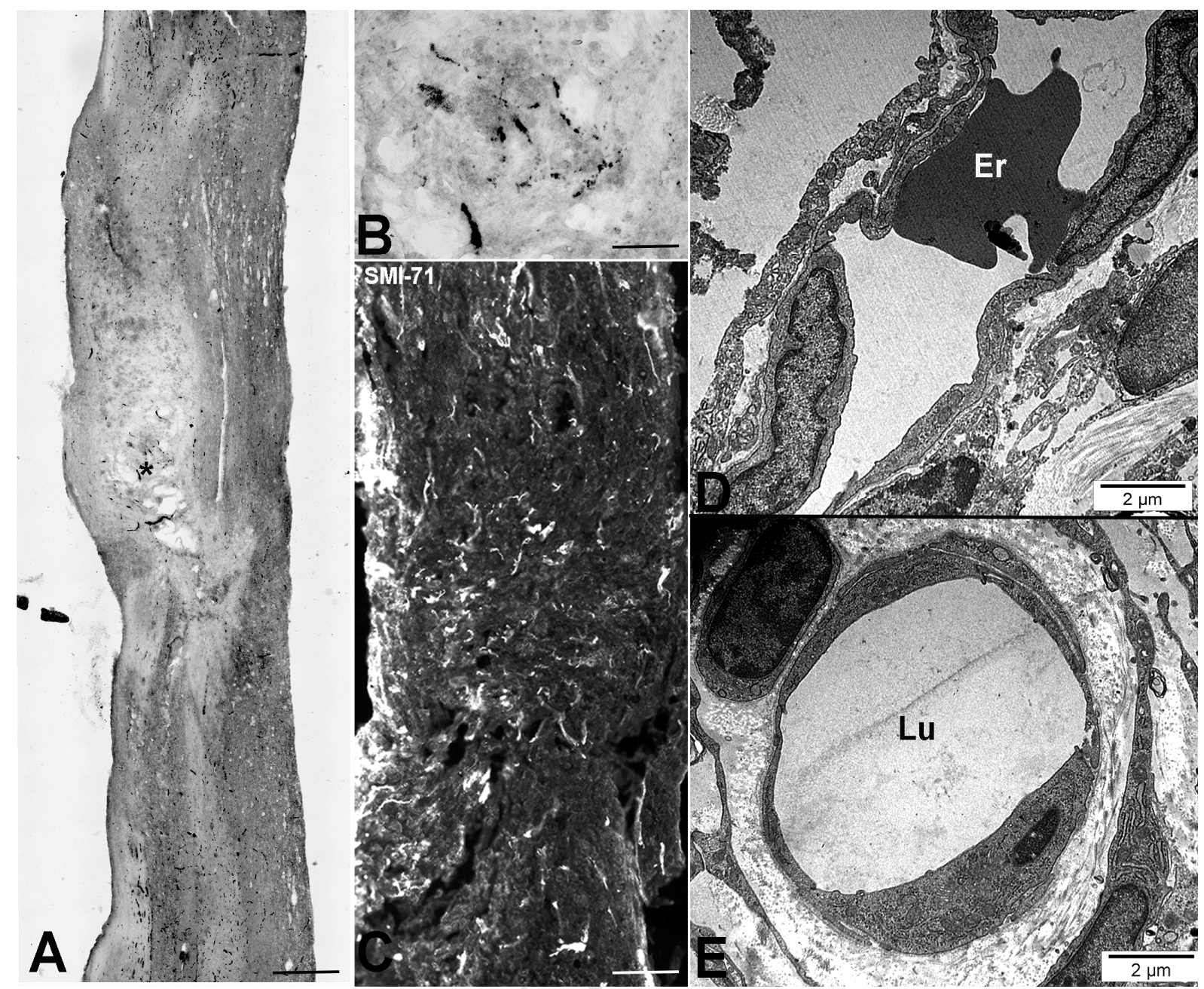


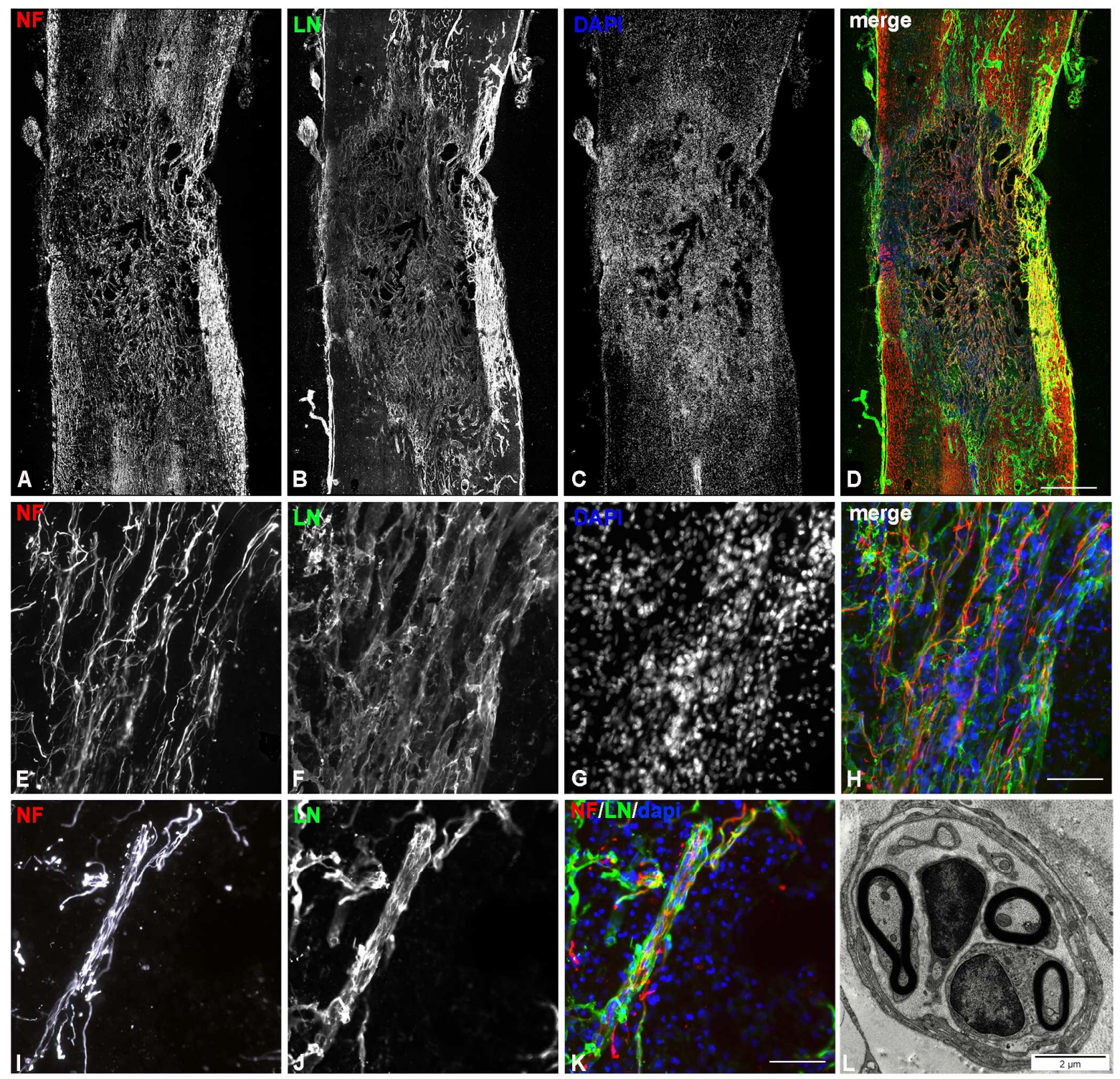




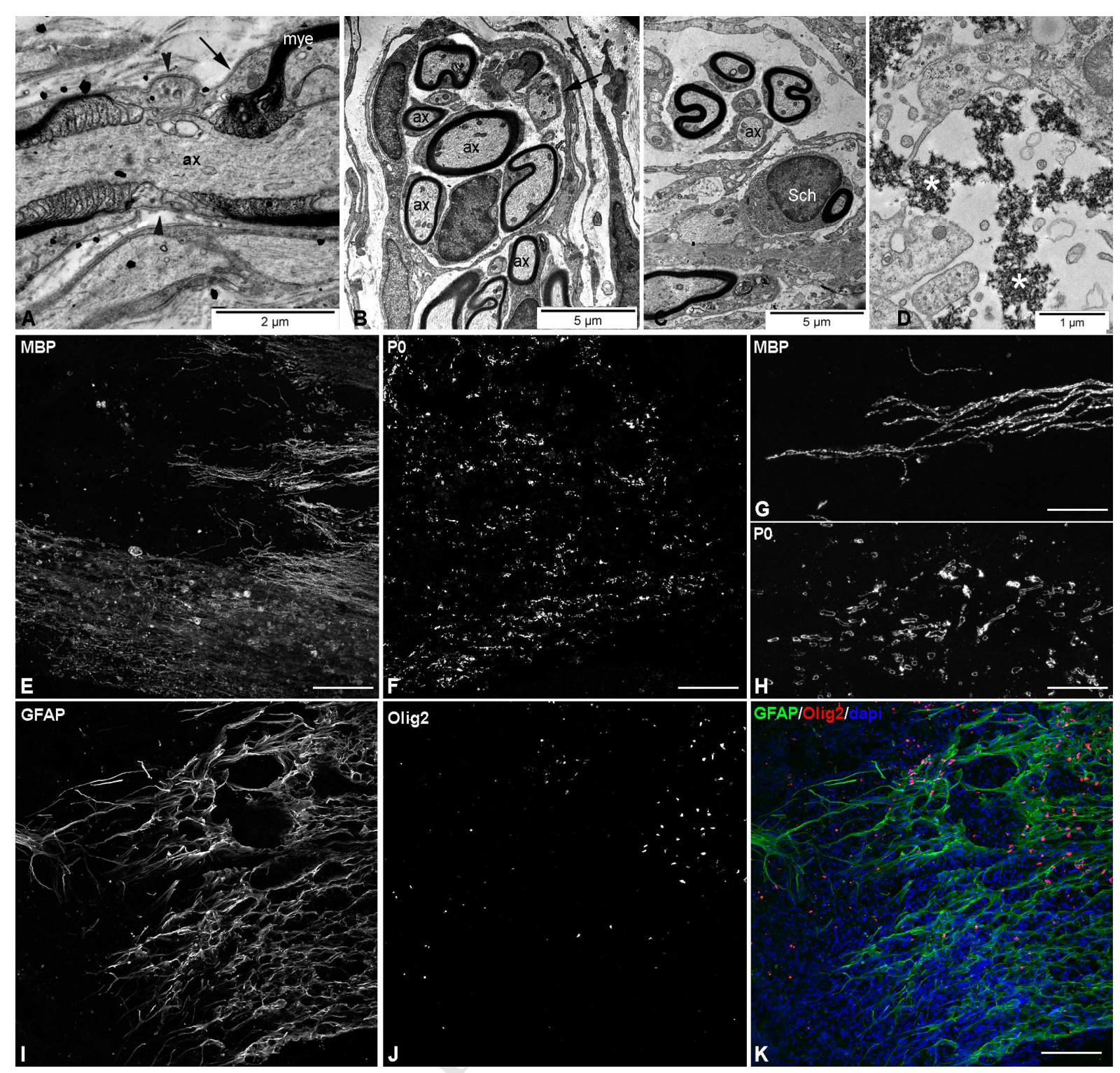




\section{ACCEPTED MANUSCRIPT}
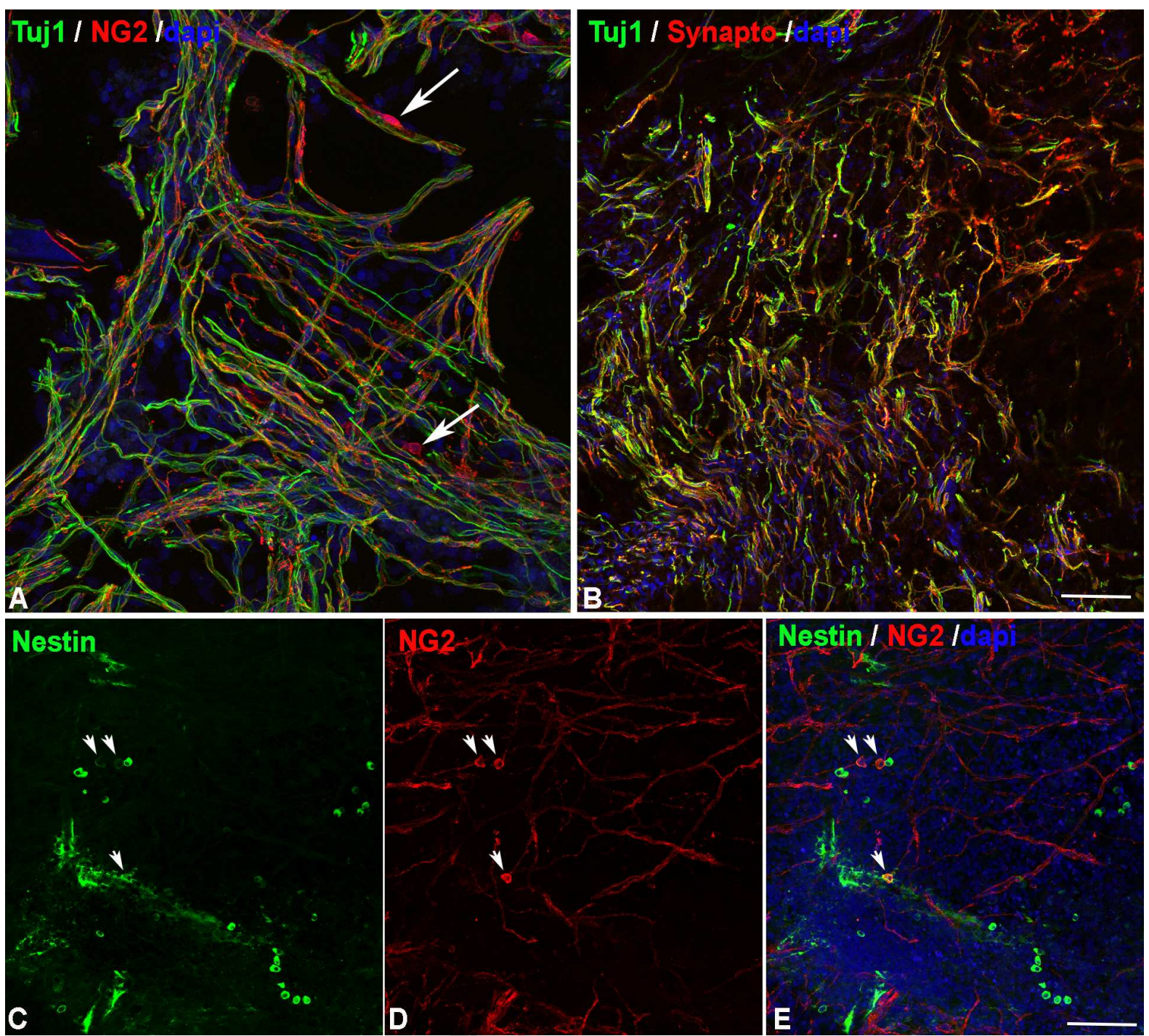


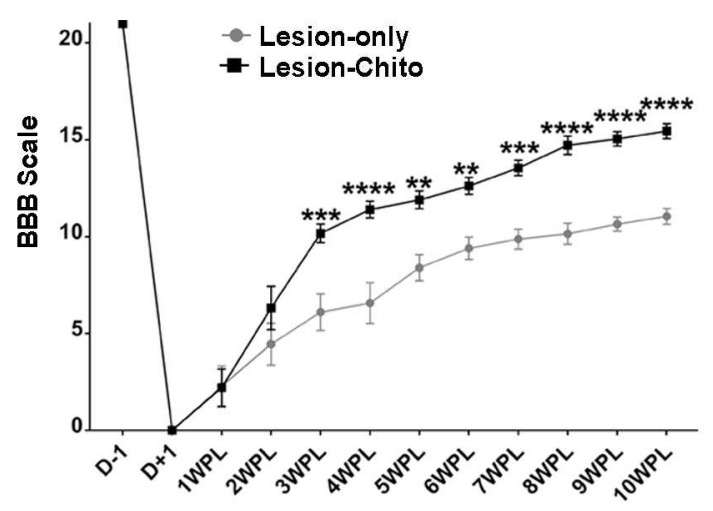

